\title{
COMPUTER CALCULATIONS ON EXPONENTIAL DATA
}

by

R. R. Haefner

Theoretical Physics Division

January 1956

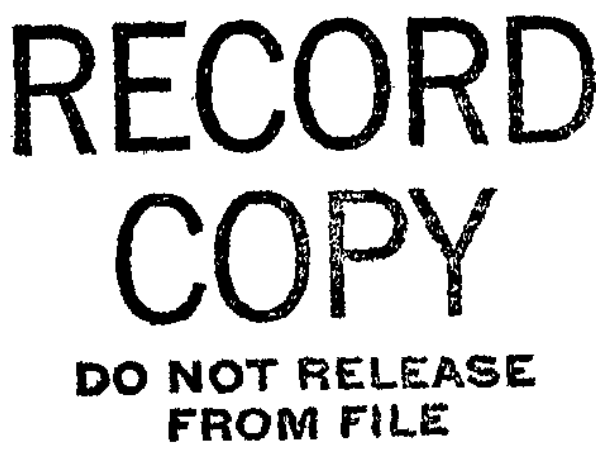

E. I. du Pont de Nemours \& Co.

Explosives Department - Atomic Energy Division Technical, Division - Savannah River Laboratory 
COMPUTER CALCULATIONS ON EXPONENTIAL DATA

by

R. R. Haefner

Theoretical Physics Division

January 1956

E. I. du Pont de Nemours \& Co.

Explosives Department - Atomic Energy Division Technical Division - Savannah River Laboratory

$$
\text { Printed for }
$$

The United States Atomic Energy Commission Contract $\operatorname{AT}(07-2)-1$ 


\section{ABSTRACT}

A routine was developed for the IBN 650 computer to obtain a least squares fit to data obtained in a subcritical reactor. The routine can obtain (1) a hyperbolic sine fit when the absolute experimental uncertainty of the data is of the same magnitude at each point, (2) a hyperbolic sine fit when the relative uncertainty is the same at each point, and (3) a $\mathrm{J}(\mathrm{kr})$ fit when the relative uncertainty is the same at each point.

External Distribution according to TID-4500 (loth Ed.) 


\section{TABLE OF CONTENTS}

$\underline{\text { Page }}$

INTRODUCTION

SUMMARY

DISCUSSION

Type 5: Relative Foil Activities - No Shutter Correction

Type 4: Relative Foil Activities - With Shutter Correction

Type 3: Radial Buckling Determination - Foil Data Only

- Type 2: Axial Buckling Determination - Foil Data Only

Type 1: Axial Buckling Determination - Traveling Monitor Data

Flowsheets and Programing

BIBLIOGRAPHY

\section{APPENDIX}

Sample Input and Output Data

IBM 650 Flowsheets 
COMPUTER CALCULATIONS ON EXPONENTIAL DATA

\section{INTRODUCTION}

The material buckling of the lattice of a thermal reactor can be determined in a subcritical assembly that has an external source of neutrons. If the lattice is contalned in a cylindrical tank with a symmetric source of neutrons at the bottom, the assembly is called an "exponential" and the neutron flux at any point in the assembly may be expressed as:

$$
\Phi(r, z)=\sum_{i=1}^{\infty} A_{1} \sinh \kappa_{i}(x-z) J_{0}\left(\frac{j_{0}, i}{R} r\right)
$$

This equation holds if the points $(r, z)$ are taken at equivalent lattice positions. Here, $\mathrm{x}$ is the extrapolated height and $\mathrm{R}$ is the extrapolated radius of the assembly; $j_{0}, i$ is the 1 th zero of $J_{0}$, the Bessel function of zero order.

If the data are taken sufficientiy far from the source, only the first term in the series is needed. The equation then becomes

$$
\Phi(r, z)=A \sinh \kappa(x-z) J_{0}\left(\frac{j_{0}, I}{R} r\right)
$$

where $j_{0,1}=2.4048$. The material buckling of the lattice is then given by $B^{2}=(2.4048 / R)^{2}-\kappa^{2}$

The manual calculation of $\kappa$ and $R$ from the experimental data taken in such an assembly is very tedious and time consuming, since many runs are made on a given lattice in order to decrease the experimental uncertainty. The use of a medium-speed or high-speed computer can eliminate the tedium and can provide results soon after the data are taken.

\section{SUMMARY}

A routine for the IBM 650 computer was developed to obtain the best fit to axial data taken with a traveling monitor(1) (Type 1), to axial data taken with foils (Type 2), and to radial data taken with foils (Type 3). The routine can also obtain relative activities of folls, corrected for epithermal neutron background (Type 4), and uncorrected (Type 5). The computations are performed in the fixed decimal mode and yield a best fit by least squares.

This code uses approximately 1550 storage locations, including 150 positions for a hyperbolic sine and $J_{0}(x)$ subroutine $(2)$, and 36 locations for an exponential subroutine 3 ? . For any given problem, a maximum of twenty experimental points can be used. The maximum value of the argument of the hyperbolic sine is 6.9. Two variations of the routine are used, one allowing greater accuracy if $\kappa(x-z) \leq 4.4$ and the other allowing $\kappa(x-z)$ to reach 9.2 , with less accuracy in the computation. 


\section{DISCUSSION}

To eliminate manual computations as much as possible, the routine to compute the bucklings was amplified by a subroutine which processed raw experimental data into numbers used by the least squares routine. The basic data desired in the latter routine were thermal neutron fluxes as a function of helght or radius in the exponential tank. Since the neutron source used at SRL ${ }^{4)}$ contributed a significant fraction of nonthermal neutrons, a correction had to be applied to the raw data. This was accomplished by obtaining neutron fluxes with and without a cadmium shutter between the source and the assembly. Subtraction of data taken with the shutter from those taken without the shutter provided the thermal neutron flux.

Neutron flux data were obtained from the activation of indium foils, or from a movable ion chamber, hereafter referred to as the "traveling monitor."(I) The foils were counted in sequence such that each foil produced approximately the same number of counts per unit counting period. Thus, it was assumed that the relative uncertainty of each experimental point was constant. The data from the traveling monitor were recorded on a Brown recorder. It was assumed that the uncertainty in these data resulted primarily from reading the chart, and was thus the same for all points, independent of the magnitude of the flux.

Five subroutines are available. The user designates his choice of one of these by inserting the digit corresponding to his problem into the proper storage.

Because it is necessary to process raw data before entering the least squares routine, the processing routines will be discussed first, followed by the three least squares routines. The numerical designation of type follows the chronological sequence of programming.

TYPE 5: RELATIVE FOIL ACTIVITIES-NO SHUTTER CORRECTION

The activity $f_{i}\left(t_{0}\right)$ of a foil at a time $t_{0}$ minutes after the completion of Irradiation is given by:

$$
f_{i}\left(t_{0}\right)=\frac{c_{i} / a}{1-\frac{c_{i} \tau}{a}} e^{\lambda\left(t_{i}-t_{0}\right)}
$$

where

$$
\begin{aligned}
& c_{i}=\text { number of counts of the ith foil, minus background } \\
& a^{=} \text {counting time in minutes for the } 1 \text { th foil } \\
& \tau=\text { counter dead time in minutes } \\
& \lambda=\text { decay constant for indium foils in min }{ }^{-1} \\
& t_{i}=\text { elapsed time in minutes from the completion of the } \\
& \text { irradiation to the commencement of counting }
\end{aligned}
$$


The subtraction of background counts from the foil counts before making the dead-time correction is a good approximation for low backgrounds.

The value of $t_{0}$ is chosen to increase the range of arguments for the exponential subroutine.

A sample input data sheet and the resultant output from a Type 402 IBM Accounting Machine are given in the Appendix. A maximum of twenty foil activities can be utilized in one run.

TYPE 4: RELATIVE FOIL ACTIVITIES-WITH SHUTTER CORRECTION

The foil activation, due to thermal neutrons, at time $t_{0}+\frac{a}{2}$ minutes after the completion of the irradiation is given by:

$$
\begin{aligned}
& f_{i}=e^{\frac{-\lambda a}{2} f_{i}\left(t_{0}\right)} \\
& =\frac{\frac{c_{i} / a}{c_{i}} e^{\lambda\left(t_{i}-t_{0}\right)}-P \frac{c_{i}^{\prime} / a^{\prime}}{a}}{1-\frac{c_{i}^{\prime} \tau}{a^{\prime}}} e^{\lambda\left(t_{i}^{\prime}-t_{0}+\frac{a^{\prime}-a}{2}\right)}
\end{aligned}
$$

$P=$ ratio of source strength for the unshuttered experiment to that for the shuttered experiment. This quantity is calculated by the IBM 650 from the relative activities within a set of normalizing foils.

Primed and unprimed variables refer to the experiments with and without a cadmium shutter, respectively.

Sample. input and output data are shown in the Appendix. Abbreviations $N S$ and $S$ refer to unshuttered and shuttered data, respectively.

TYPE 3: RADIAI BUCKLING DETERMINATION-FOIL DATA ONLY

The extrapolated radius of the subcritical assembly, $R$, was obtained by assuming that the thermal neutron flux could be fitted by the fundamental Bessel function $J_{0}(\kappa r)$, where $R=2.4048 / \kappa$.

The data were obtained from foils, each counted at such a time that all foils had the same relative uncertainty. Thus in fitting the theoretical curve by a least squares analysis, the relative error was minimized. The condition which applies to this treatment demands that

$$
E_{3}=\sum_{i=1}^{N}\left(\frac{f_{i}}{A J_{0}\left(k r_{i}\right)}-1\right)^{2} \quad \text { be a minimum. }
$$


By setting $\frac{\partial E_{3}}{\partial A}=0$ and $\frac{\partial E_{3}}{\partial \kappa}=0$, one obtains

$$
g_{3}(\kappa)=\sum_{i=1}^{N}\left(A J_{0}\left(\kappa r_{i}\right)-f_{i}\right) \frac{f_{i} r_{i} J_{1}\left(\kappa r_{i}\right)}{\left[J_{0}\left(\kappa r_{i}\right)\right]^{3}}=0
$$

where

$$
A=\sum_{i=1}^{N} \frac{f_{i}^{2}}{\left[J_{0}\left(\kappa r_{i}\right)\right]^{2}} \div \sum_{i=1}^{N} \frac{f_{i}}{J_{0}\left(\kappa r_{i}\right)}
$$

The routine computes $\mathrm{g}_{3}\left(\kappa_{1}\right)=\alpha_{1}, \mathrm{~g}_{3}\left(\kappa_{2}\right)=\alpha_{2}$, and Iinearly extrapolates or interpolates from these results to obtain $\kappa_{3}$. Then, from $g_{3}\left(\kappa_{3}\right)=\alpha_{3}$, and $g_{3}\left(\kappa_{2}\right)=\alpha_{2}$, one obtains $\kappa_{4}$. by the same process. The system is considered to have converged when $\left|\kappa_{n+1}-\kappa_{n}\right| \leq 10^{-4}$.

Sample input and output information are given in the Appendix. The relative error at each point, $f_{i} / J_{0}\left(k r_{i}\right)$, is included in the print-out, as well as $\epsilon^{2}=\frac{1}{N-2}\left(\sum_{i=1}^{N}\left[f_{i}-A_{0}\left(\kappa r_{i}\right)\right]^{2}\right)$

TYPE 2: AXIAL BUCKLING DETERMINATION-FOIL DATA ONLY

The data obtained from the foils in the exponential should fit a curve $A$ sinh $\kappa\left(x-z_{i}\right)$ in the vertical direction. Previous experience with an IBM Card Programmed Calculator had shown that a threeparameter fit for $A, K$, and $x$ led to values of $x$ that were incompatible with the value of moderator height plus the theoretical extrapolation distance, which is 0.71 times the transport mean free path for the moderator. Thus, the routine was developed to obtain a least squares fit for $A$ and $\kappa$. The value of $x$ was supplied by the user of the routine.

The system of foil counting was the same for Type 2 runs as for Type 3. Thus, it was required that

$$
E_{2}=\sum_{i=1}^{N}\left[\frac{f_{i}}{A \sinh \kappa\left(x-z_{i}\right)}-1\right]^{2} \text { be a minimum. }
$$

By setting $\frac{\partial E_{2}}{\partial A}=0$ and $\frac{\partial E_{2}}{\partial \kappa}=0$ one obtains 
$g_{2}(\kappa)=\sum_{i=1}^{N}\left[A \sinh \kappa\left(x-z_{i}\right)-f_{i}\right] \frac{f_{i}\left(x-z_{1}\right) \cosh \kappa\left(x-z_{i}\right)}{\sinh ^{3} \kappa\left(x-z_{i}\right)}=0$

where

$$
\left.A=\sum_{i=1}^{N} \frac{f_{i}^{2}}{\left[\sinh \kappa\left(x-z_{1}\right)\right.}\right]^{2} \div \sum_{i=1}^{N} \frac{f_{i}}{\sinh \kappa\left(x-z_{i}\right)}
$$

The routine to obtain $\kappa$ is iterative, and similar to that for Type 3. Three separate routines are available. They are used when $\operatorname{Max}[k(\mathrm{x}-\mathrm{z})] \leq 4.4, \leq 7.5$, and $\leq 9.2$. The accuracy in the computation of $k$ decreases when the larger values of the function are encountered.

Sample input and output data are shown in the Appendix. It should be noted that $\epsilon^{2}$ is not the function that is minimized, since

$$
\epsilon^{2}=\frac{1}{N-2} \sum_{i=1}^{N}\left[f_{i}-A \sinh \kappa\left(x-z_{i}\right)\right]^{2}
$$

TYPE 1: AXIAL BUCKLING DETERMINATION-FOR TRAVELING MONITOR RESULTS

A value of the axial buckling, $-\kappa^{2}$, was obtained from traveling monitor results by fitting the data to a curve of the form A sinh $\kappa(x-z)$. Again, the least squares fit was obtained for $A$ and $\kappa$, while the value of $x$ was supplied by the user of the routine. Limitations on $\kappa$ are the same as given for Type 2. Since the absolute error in $f_{1}$ was the same for each value of $z_{i}$, the quantity

$$
E_{1}=\sum_{i=1}^{N}\left[f_{i}-A \sinh x\left(x-z_{i}\right)\right]^{2}
$$

was required to be a minimum. For $\frac{\partial E_{1}}{\partial A}=0$, and $\frac{\partial E_{1}}{\partial \kappa}=0$,

$$
g_{1}(\kappa)=\sum_{i=1}^{N}\left[A \sinh \kappa\left(x-z_{i}\right)-f_{i}\right]\left(x-z_{i}\right) \cosh \kappa\left(x-z_{i}\right)=0
$$

where

$$
A=\sum_{i=1}^{N} f_{i} \sinh \kappa\left(x-z_{i}\right) \div \sum_{i=1}^{N} \sinh \kappa\left(x-z_{i}\right)
$$

Sample input and output data are given in the Appendix. 


\section{FLOWSHEETS AND PROGRAMMING}

the IBM 650.

The Appendix contains the flowsheets used in the programming. The L-1 load routine(5) is used to read the input data into

Copies of the program deck and details of the programming are available upon request.

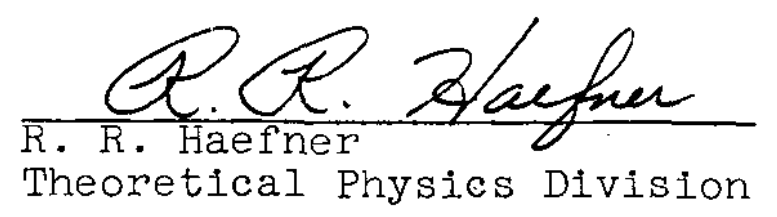

\section{BIBLIOGRAPHY}

1. Johnson, L. M. A Traveling Monitor for an Exponential Pile. E. I. du Pont de Nemours and Co., DP-51, October 1955.

2. Baxter, W. V. IBM 650 Sub-routines I. E. I. du Pont de Nemours and Co., DP-124, July 1955 .

3. Trimble, G. R., Jr. "Subroutines for the IBM Type 650." IBM Technical Newsletter No. 9, p. 49.

4. Axtmann, R. C. and Towler, O. A., Jr. E. I. du Pont de Nemours and Co. DP-49, October 1954 (Classified Report).

5. Trimble, G. R., Jr., and Kubie, E. C. "IBM Type 650 Loading Routines." IBM Technical Newsletter No. 8, p. 47. 
SAMPLE INPUT DATA TYPE 1
Run No. 1076

Without Shutter

REMARKS

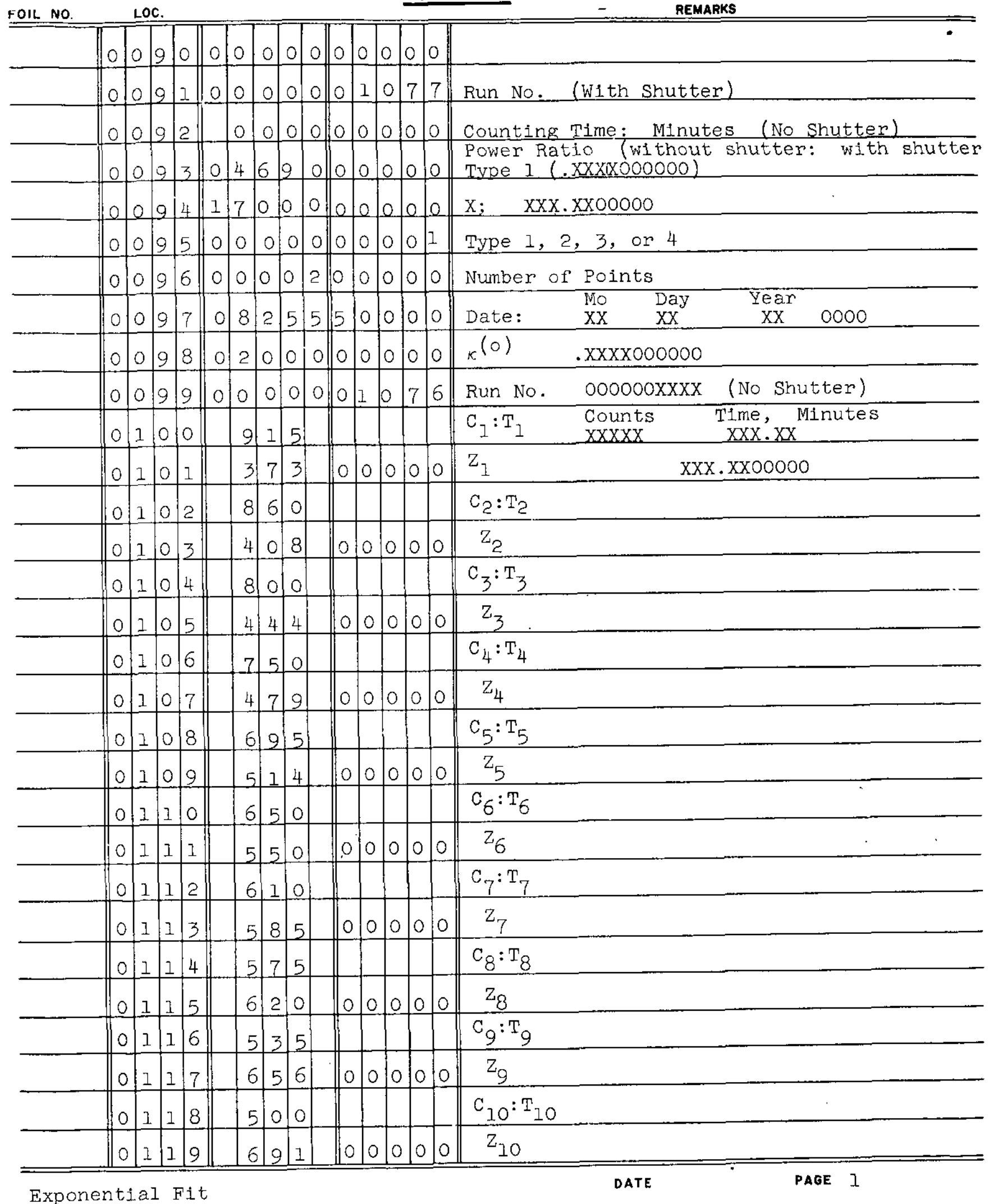


Type 1

Run No. 1076 (Continued)

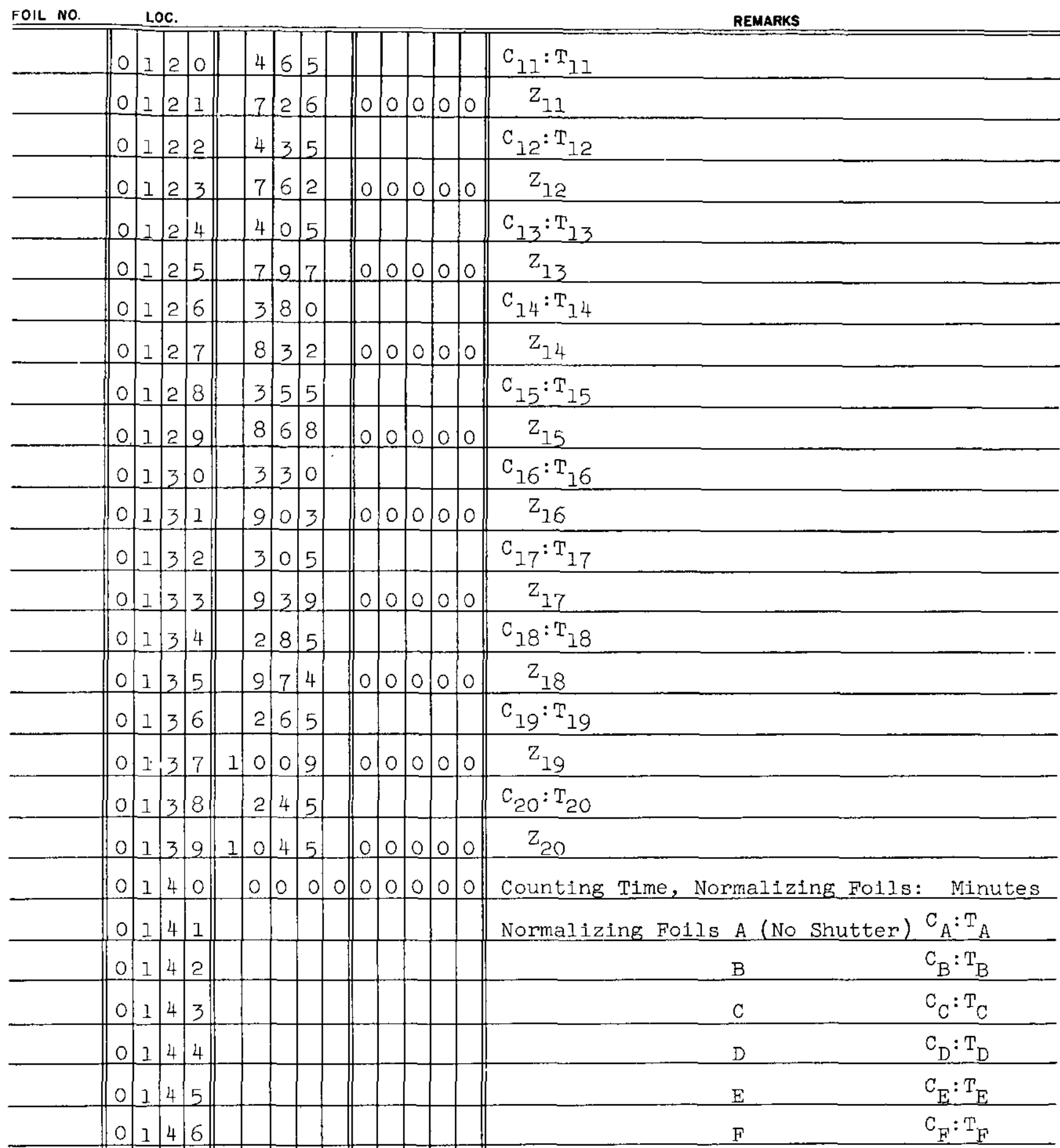

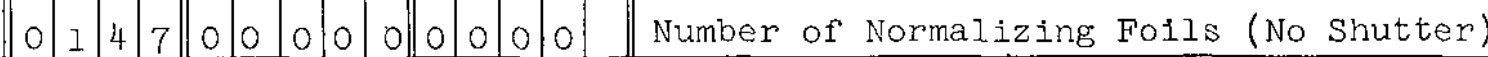


Run No.

W1th Shutter

FOIL. NO

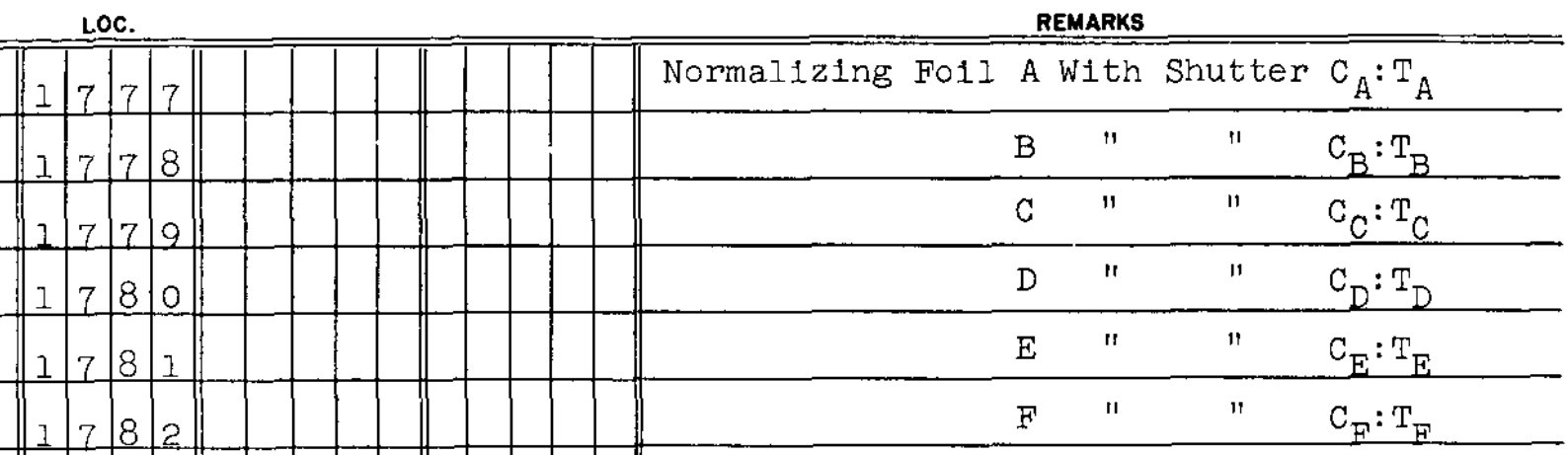

\begin{tabular}{llll|lllllll|lllllll}
1 & 7 & 8 & 3 & 0 & 0 & 0 & 0 & 0 & 0 & 0 & 0 & 0 & 0 \\
\hline
\end{tabular}

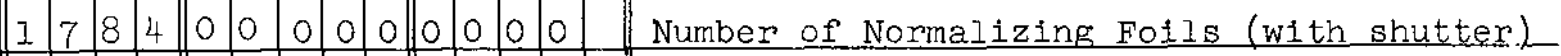

\begin{tabular}{llll|lllll|lllll|lll}
1 & 7 & 8 & 5 & 0 & 0 & 0 & 0 & 0 & 0 & 0 & 0 & 0 & Counting Time, Shutter Run: Minutes
\end{tabular}

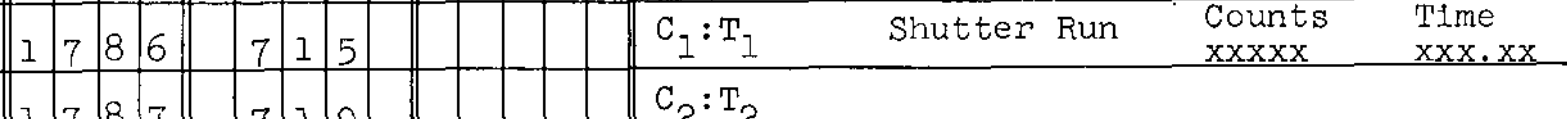

\begin{tabular}{llll|l|l|l|l|l|l|l||l|l|l|l}
1 & 7 & 8 & 7 & 7 & 1 & 0 & $\mathrm{C}_{2}: \mathrm{T}$ \\
\hline
\end{tabular}

\begin{tabular}{lllllllllll|l}
1 & 7 & 8 & 8 & 7 & 0 & 5 & & & & & $\mathrm{C}_{3}: \mathrm{T}_{3}$ \\
\hline
\end{tabular}

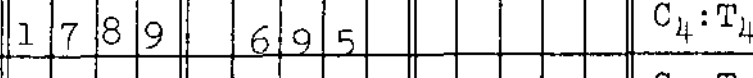

$17900 \quad 6.900 \quad 0 \quad C_{5}: T_{5}$

$1791 \quad 6.800 \quad \mathrm{C}_{6}: \mathrm{T}_{6}$

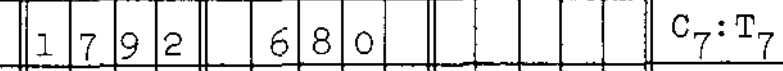

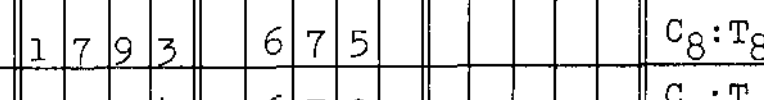

\begin{tabular}{llll|llllllllll|l}
1 & 7 & 9 & 4 & 6 & 7 & 0 & & & & & & $\mathrm{C}_{9}: \mathrm{T}_{9}$ \\
\hline
\end{tabular}

$1795 \quad 6600 \quad+\mathrm{C}_{10}: \mathrm{T}_{10}$

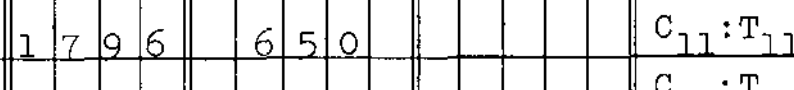

\begin{tabular}{lllllllllllll}
1 & 7 & 9 & 7 & 6 & 4 & 5 & & & & & & $\mathrm{C}_{12}: \mathrm{T}_{12}$ \\
\hline
\end{tabular}

\begin{tabular}{llll|l|l|l|l|l|l|l}
1 & 7 & 9 & 8 & 6 & 4 & 0 & $\mathrm{C}_{13}: \mathrm{T}_{13}$
\end{tabular}

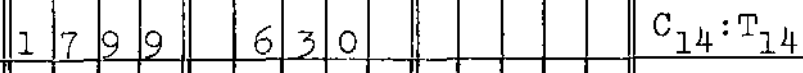

$1800620 \quad \quad \mathrm{C}_{15}: \mathrm{T}_{15}$

$18001 \quad 61100 \quad 0 \quad \mathrm{C}_{16}: \mathrm{T}_{16}$

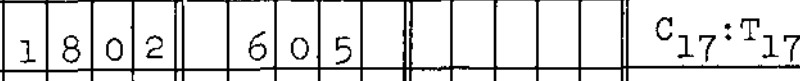

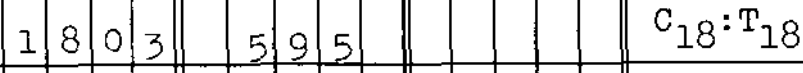

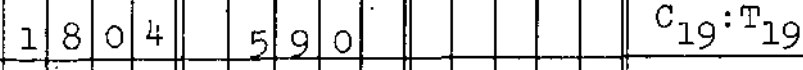

\begin{tabular}{lllllllllll|l}
1 & 8 & 0 & 5 & 5 & 8 & 0 & & & & & $\mathrm{C}_{20}: \mathrm{T}_{20}$ \\
\end{tabular} 
PRINT-OUT FOR TYPE I

z NS Chart Reading

$37 \cdot 3$

44.4

47.9

51.4

55.0

58.5

62.0

65.6

69.1

72.6

76.2

79.7

83.2

86.8

90.3

93.9

97.4

100.9

104.5

2

$37 \cdot 3$

44.4

47.9

51.4

55.0

58.5

62.0

65.6

69.1

72.6

76.2

79.7

83.2

86.8

90.3

93.9

97.4

100.9

104.5

8-25

Date
09150

08600

08000

07500

06950

06500

06100

$0575^{\circ}$

05350

05005

04650

04350

04055

03800

03555

03300

03050

02850

02653

02459

$f_{1}$

0.8814

0.8267

0.7669

0.7174

0.6626

0.6181

0.5781

0.5433

0.5035

0.4695

0.4345

0.4047

0.3754

0.3504

0.3264

0.30 .13

0.2766

0.2570

0.2376

0.2186

$551 \quad .01955170$

Type Kappa X
S Chart Reading

07150

07100

07050

06950

06900

06800

06800

06750

06700

06600

06500

06450

06400

06300

06200

06100

06050

05950

05900

05800

$f_{i} / A \sinh$

NS Run \#

0.9980

1.0031

0.9995

1.0024

0.9928

0.9951

0.9984

1.0068

1.0035

1.0055

0.9984

I. 0023

0.9986

1.0026

1.0083

1.0019

0.9936

0.9968

0.9968

0.9952

1076

1076

1076

1076.

1076

1076

1076

1076

1076

1076

1076

1076

1076

1076

1076

1076

1076

1076

1076

1076

000.0047

1077

$E^{2}$

S Run \#
00000

00000

00000

00000

00000

00000

00000

00000

00000

00000

00000

00000

00000

00000

00000

00000

00000

00000

00000

00000

Pwr. Ratio

.04690

.04690

.04690

.04690

.04690

.04690

.04690

.04690

.04690

.04690

.04690

.04690

.04690

.04690

.04690

.04690

.04690

.04690

.04690

.04690

.13224

A 
SAMPLE INPUT DATA TYPE 2
Run No. $\quad 1084$

Without Shutter

REMARKS

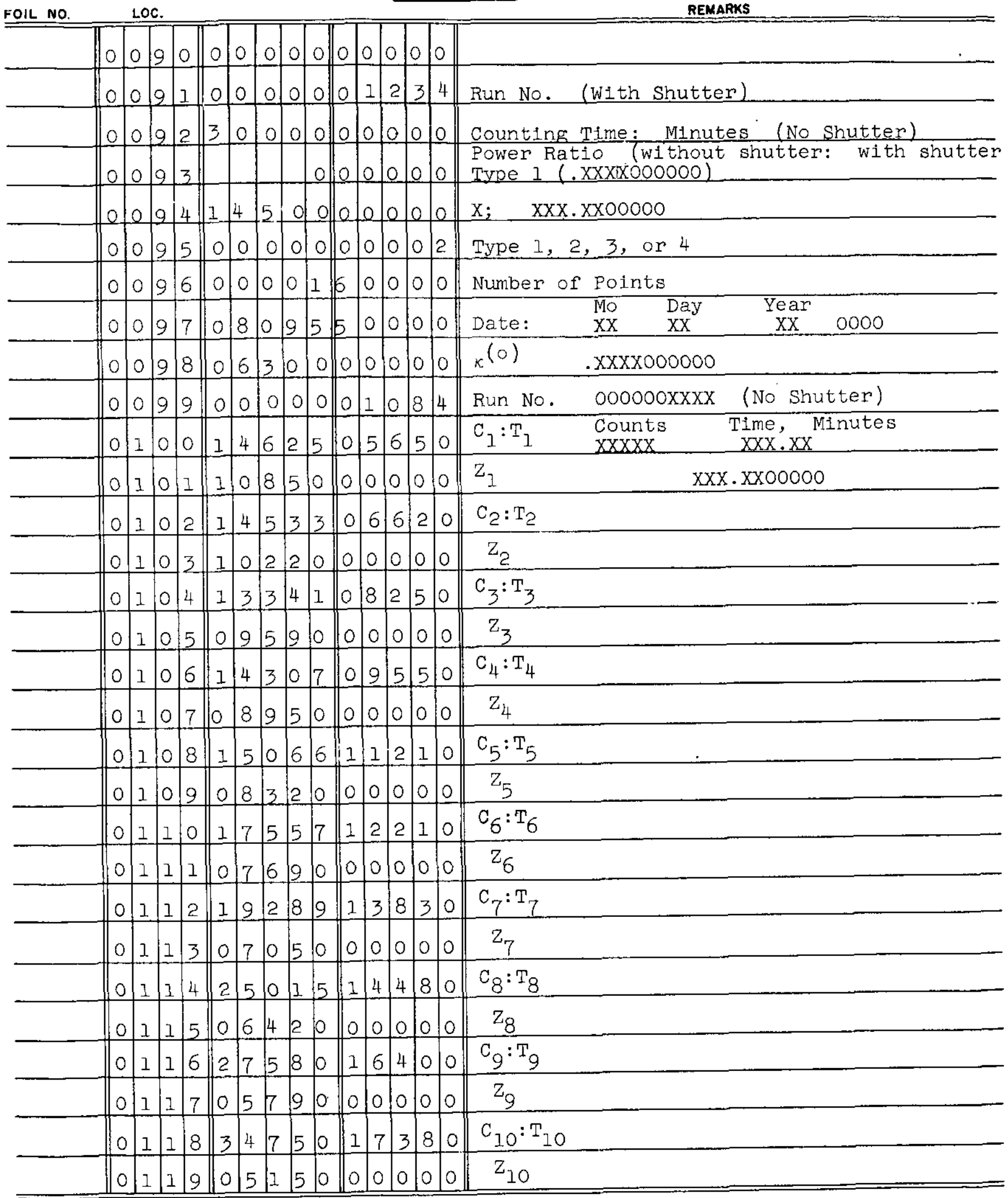

Exponential Fit 
Type 2

Run No. 1084 (Continued)

FOIL NO.

\begin{tabular}{|lll|l|l|l|l|l|l|l|l|l|l|l||l}
\hline 0 & 1 & 2 & 0 & 4 & 0 & 3 & 9 & 6 & 1 & 9 & 0 & 7 & 0 & $\mathrm{C}_{11}: \mathrm{T}_{11}$
\end{tabular}

REMARKS

\begin{tabular}{lllll|lllll|lllllll}
0 & 1 & 2 & 1 & 0 & 4 & 5 & 2 & 0 & 0 & 0 & 0 & 0 & 0 & $z_{11}$
\end{tabular}

$\begin{array}{llllllllllllllllllllllllll}0 & 1 & 2 & 2 & 5 & 1 & 7 & 3 & 9 & 2 & 0 & 0 & 8 & 0 & C_{12}: T_{12}\end{array}$

\begin{tabular}{llll|lllll|lllllllllllll}
0 & 1 & 2 & 3 & 0 & 3 & 8 & 8 & 0 & 0 & 0 & 0 & 0 & 0 & $z_{12}$ \\
\hline
\end{tabular}

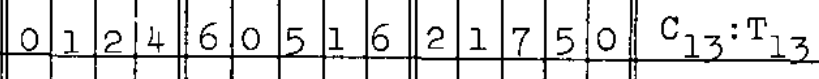

$\begin{array}{llllllllllllllllllllllllll}0 & 1 & 2 & 5 & 0 & 3 & 2 & 5 & 0 & 0 & 0 & 0 & 0 & 0 & z_{13}\end{array}$

$\begin{array}{llllllllllllllllllllllllllll}0 & 1 & 2 & 6 & 5 & 7 & 2 & 0 & 2 & 2 & 5 & 4 & 5 & 0 & C_{14}: T_{14}\end{array}$

\begin{tabular}{llll|lllll|llllllllllll}
0 & 1 & 2 & 7 & 0 & 2 & 6 & 1 & 0 & 0 & 0 & 0 & 0 & 0 & $z_{14}$
\end{tabular}

\begin{tabular}{llll|lllll|lllll|l}
0 & 1 & 2 & 8 & 4 & 6 & 1 & 8 & 7 & 3 & 0 & 2 & 5 & 0 & $C_{15}: T_{15}$
\end{tabular}

\begin{tabular}{lllllllll|llllllllllllll}
0 & 1 & 2 & 9 & 0 & 1 & 9 & 8 & 0 & 0 & 0 & 0 & 0 & 0 & $z_{15}$
\end{tabular}

$\begin{array}{llllllllllllllllllllllllll}0 & 1 & 3 & 0 & 6 & 1 & 0 & 6 & 7 & 3 & 1 & 2 & 4 & 0 & C_{16}: T_{16}\end{array}$

$0 \begin{array}{llllllllllllllll}0 & 3 & 1 & 0 & 1 & 3 & 5 & 0 & 0 & 0 & 0 & 0 & 0 & z_{16}\end{array}$

\begin{tabular}{llll|lll|l|l|l||l|l|l|l|l|l}
0 & 1 & 3 & 2 & & & & & & & & $\mathrm{C}_{17}: \mathrm{T}_{17}$ \\
\hline
\end{tabular}

\begin{tabular}{llll|lllllllllllllll}
0 & 1 & 3 & 3 & & & & 0 & 0 & 0 & 0 & $z_{27}$
\end{tabular}

$0.134-10 \quad 0 \quad 0 \quad 0 \quad \mathrm{C}_{18}: \mathrm{T}_{18}$

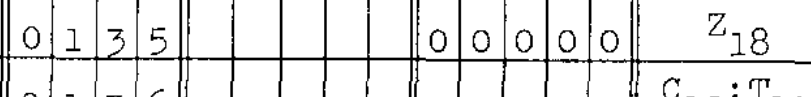

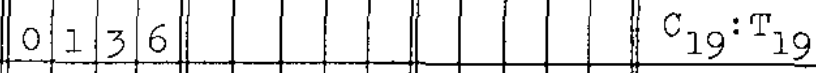

$\begin{array}{llllllllllllllllllllllllll}0 & 1 & 3 & 7 & & & & 0 & 0 & 0 & 0 & 0 & z_{19}\end{array}$

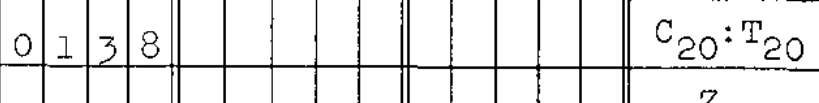

$\begin{array}{llllllllllllll}0 & 1 & 3 & 9 & & & & 0 & 0 & 0 & 0 & z_{20}\end{array}$

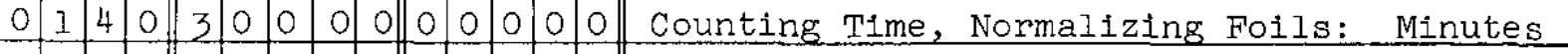

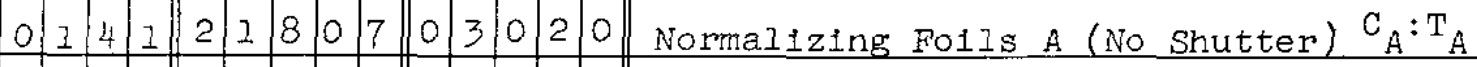

\begin{tabular}{llll|lllll|lllll|llll}
0 & 1 & 4 & 2 & 2 & 1 & 0 & 9 & 1 & 0 & 3 & 3 & 5 & 0 & & $C_{B}: T_{B}$
\end{tabular}

\begin{tabular}{llll|llll|llllll|llll}
0 & 1 & 4 & 3 & 1 & 9 & 6 & 4 & 9 & 0 & 3 & 6 & 7 & 0 & $\mathrm{C}$ & $\mathrm{C}_{\mathrm{C}}: \mathrm{T}_{\mathrm{C}}$
\end{tabular}

\begin{tabular}{llll|lllll|llllll|llll}
0 & 1 & 4 & 4 & 1 & 9 & 4 & 3 & 4 & 0 & 4 & 0 & 0 & 0 & $C_{D}: T_{D}$
\end{tabular}

\begin{tabular}{llll|lllll|lllll|llll}
0 & 1 & 4 & 5 & 1 & 9 & 1 & 7 & 6 & 0 & 4 & 3 & 3 & 0 & $\mathrm{C}_{E}: \mathrm{T}_{\mathrm{E}}$
\end{tabular}

\begin{tabular}{llll|llllll|lllllll|llll}
0 & 1 & 4 & 6 & 1 & 7 & 5 & 0 & 6 & 0 & 4 & 6 & 6 & 0 & $F$ & $C_{F}: T_{F}$
\end{tabular}

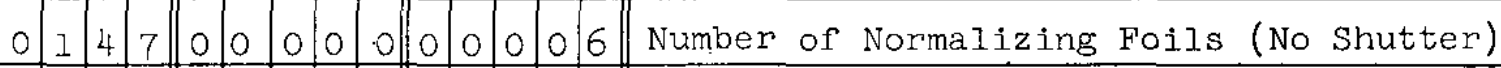


FOIL NO.

REMARKS

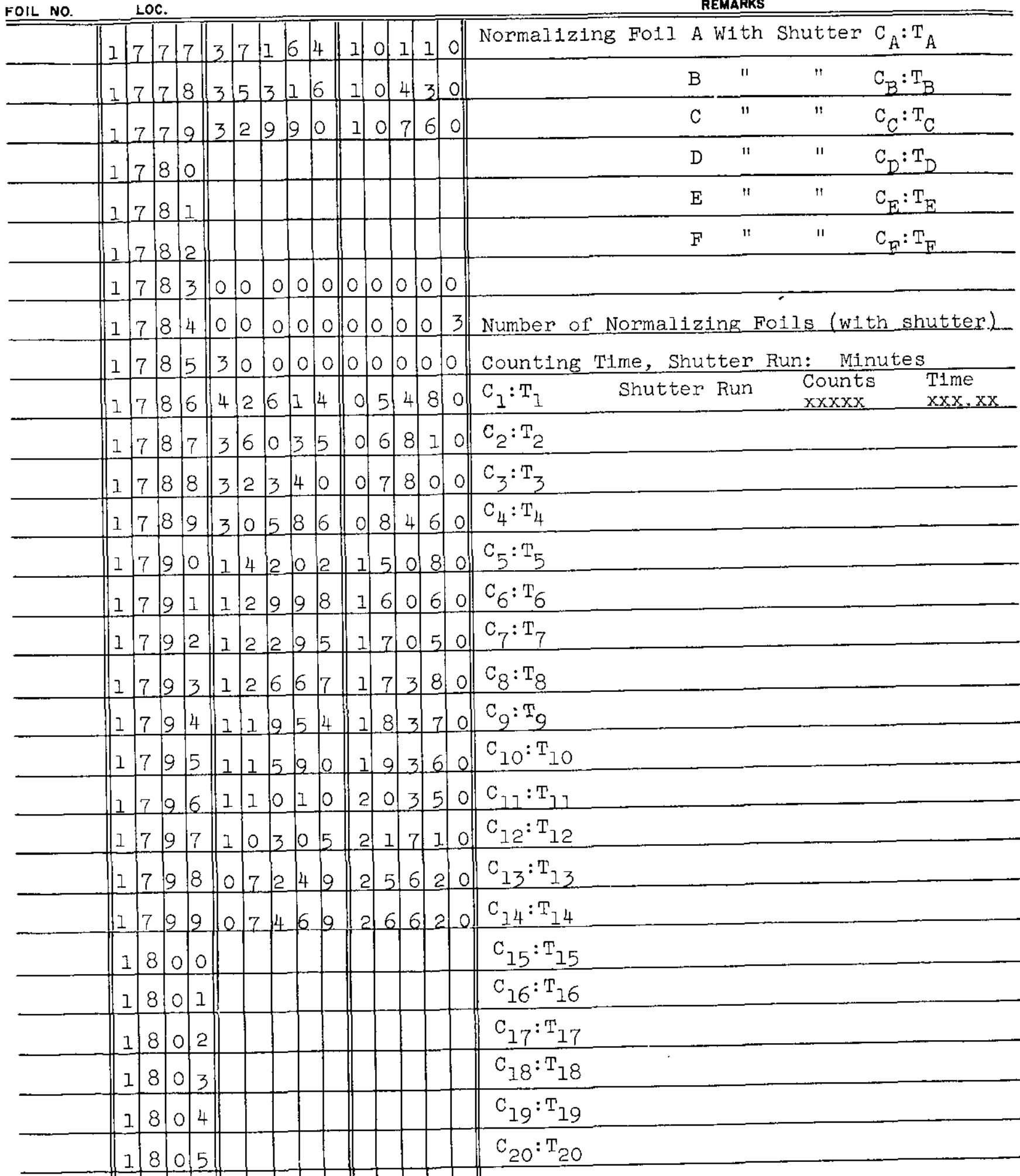


PRINT-OUT FOR TYPE 2

No. of Norm. Foils NS Norm. Foil Data

S Norm. Foll Data

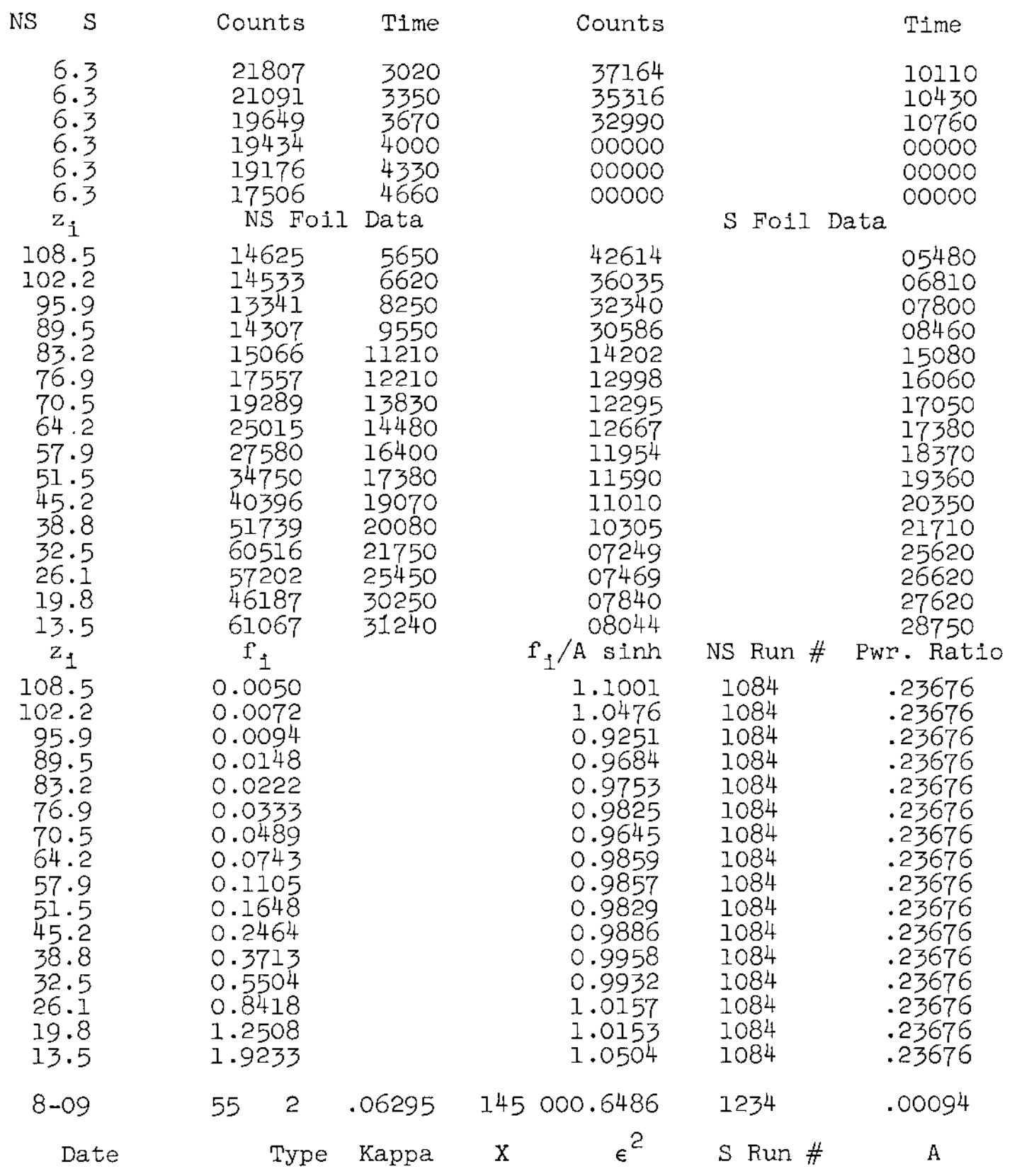


SAMPLE INPUT DATA TYPE 3

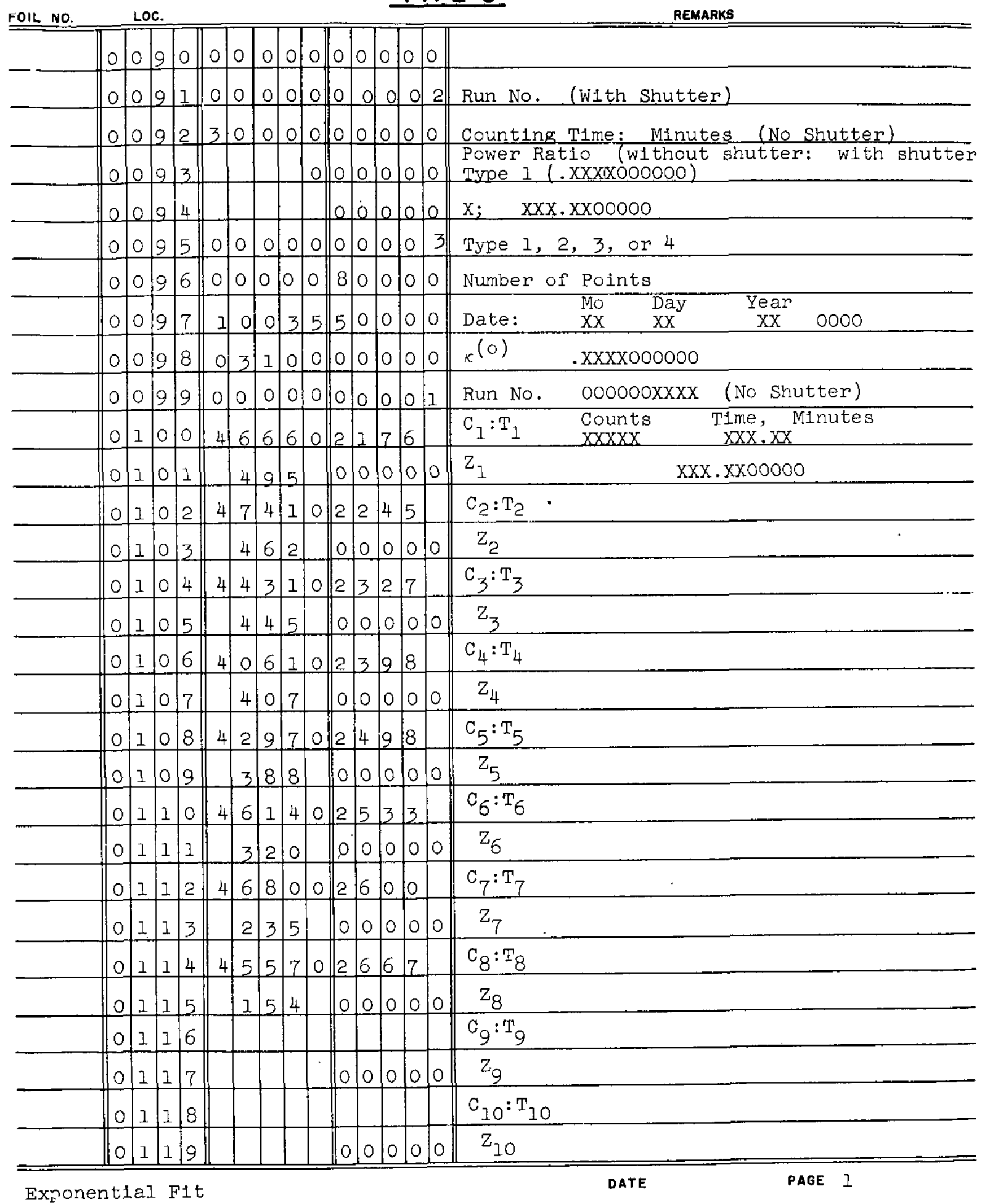

Run No. 0001

Without Shutter 
Type 3

Run No. 0001 (Continued)

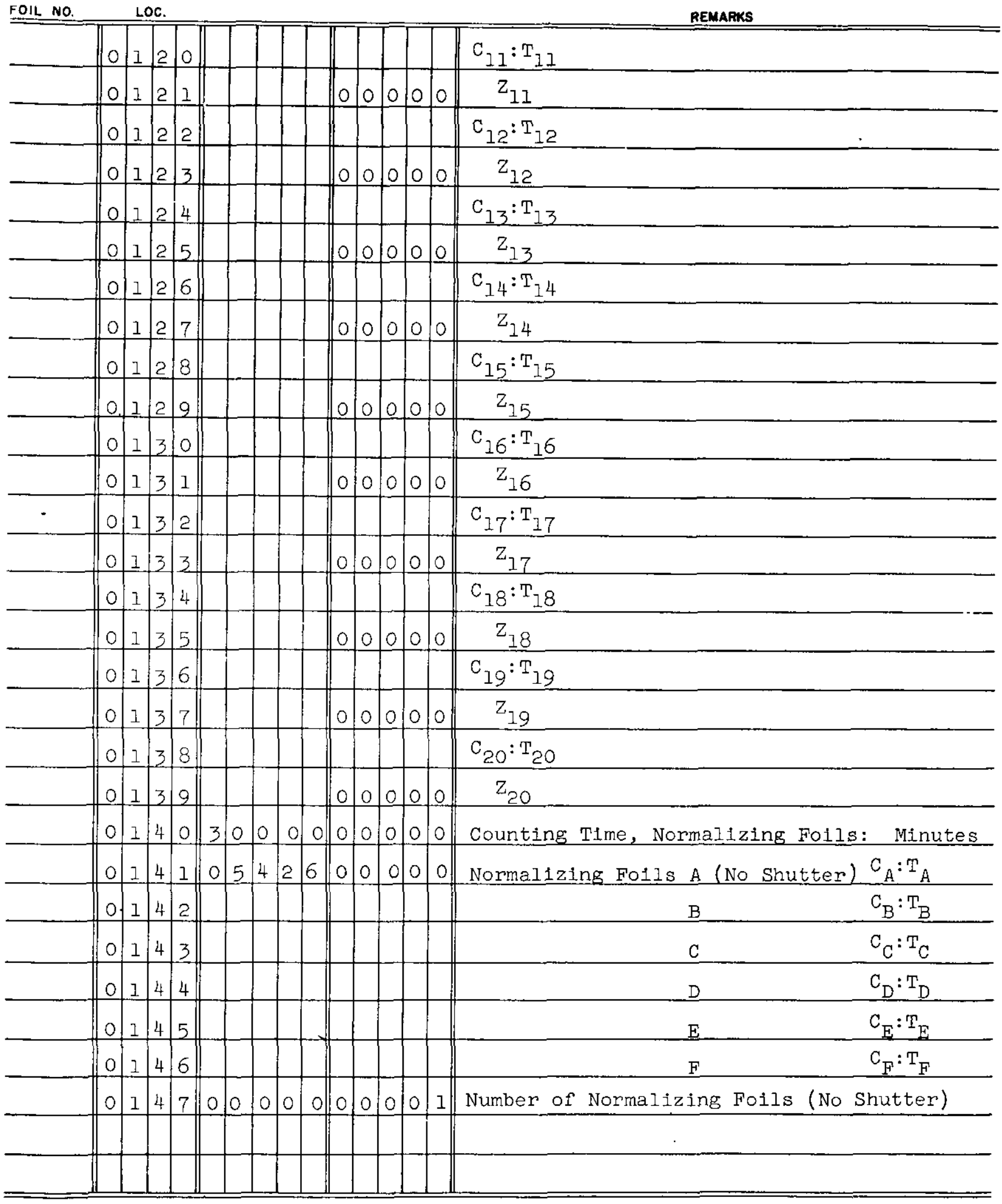


Run No. 0002

With Shutter

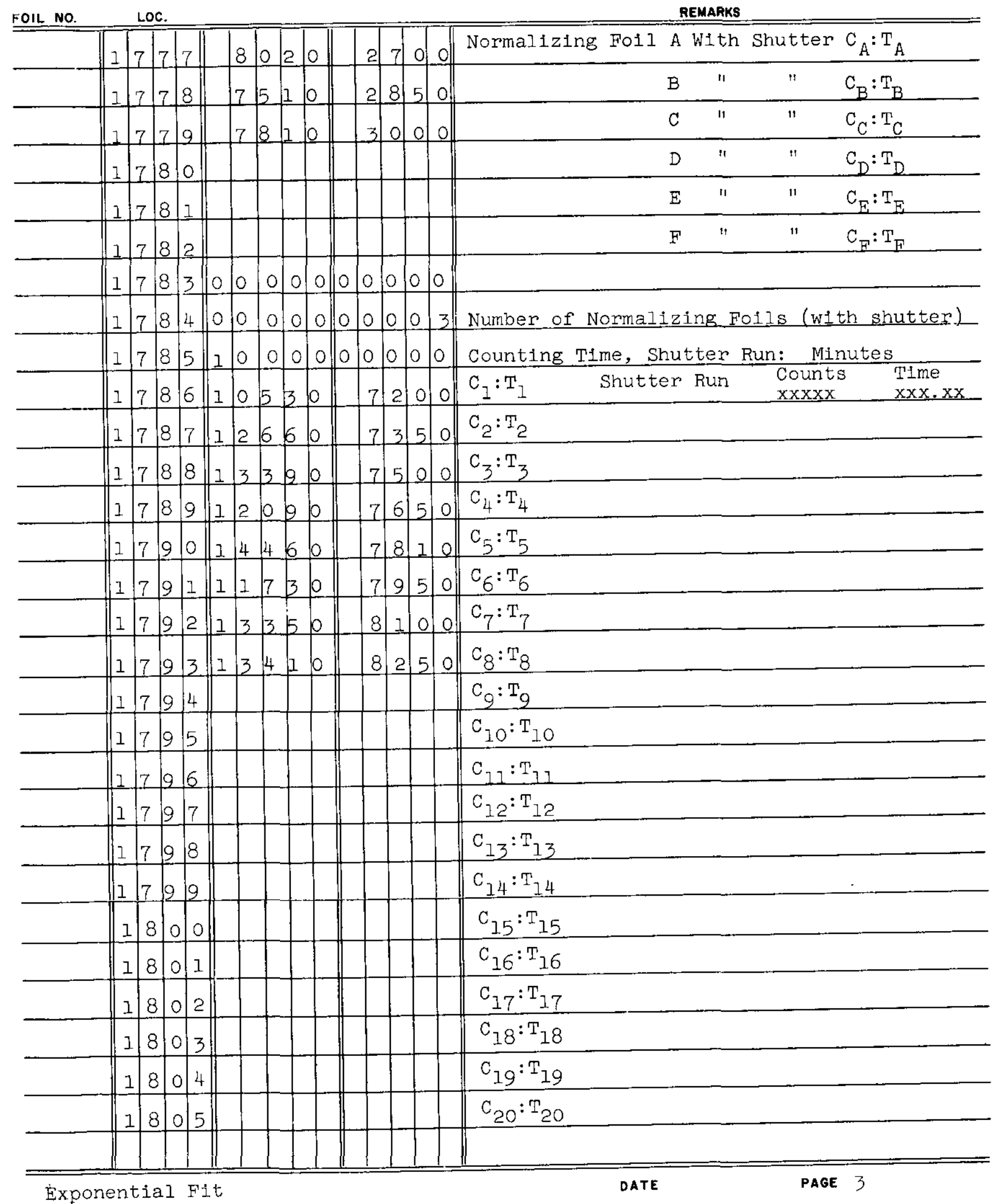


No. of Norm. Foils NS Norm. Foil Data NS

1.3
1.3
1.3
1.3
1.3
1.3
$r_{1}$
49.5
46.2
44.5
40.7
38.8
32.0
23.5
15.4
$r 1$
49.5
46.2
44.5
40.7
38.8
32.0
23.5
15.4
$10-03$

Date

$\begin{array}{cc}\text { Counts } & \text { Time } \\ 05426 & \\ 00000 & \\ 00000 & \\ 00000 & \\ 00000 & \\ 00000 & \\ \text { NS Foil } & \text { Data } \\ 46660 & 21760 \\ 47410 & 22450 \\ 44310 & 23270 \\ 40610 & 23980 \\ 42970 & 24980 \\ 46140 & 25330 \\ 46800 & 26000 \\ 45570 & 26670 \\ f 1 & \end{array}$

0.4159

0.4595

0.4742

0.4764

0.5740

0.6570

0.7252

0.7695
S Norm. Foll Data

$\begin{array}{ccc}\text { Counts } & & \text { Time } \\ 08020 & & 02700 \\ 07510 & & 02850 \\ 07810 & & 03000 \\ 00000 & & 00000 \\ 00000 & & 00000 \\ 00000 & & 00000 \\ & \text { S Foil Data } \\ 10530 & & 07200 \\ 12660 & & 07350 \\ 13390 & & 07500 \\ 12090 & & 07650 \\ 14460 & & 07810 \\ 11730 & & 07950 \\ 13350 & & 08100 \\ 13410 & & 08250 \\ f_{1} / \mathrm{A} J 0 & \text { NS Run \# } & \text { Pwr. Ratio } \\ 1.0221 & 1 & .47991 \\ 1.0121 & 1 & .47991 \\ 0.9925 & 1 & .47991 \\ 0.9002 & 1 & .47991 \\ 1.0364 & 1 & .47991 \\ 1.0330 & 1 & .47991 \\ 1.0053 & 1 & .47991 \\ 0.9850 & 1 & .47991 \\ 0.6516 & 2 & .08279 \\ \epsilon 2 & \text { S Run \# } & 10-1 \mathrm{~A} \\ \epsilon & & \end{array}$


SAMPLE INPUT DATA TYPE 4
Run No. 0001

Without shutter

REMARKS

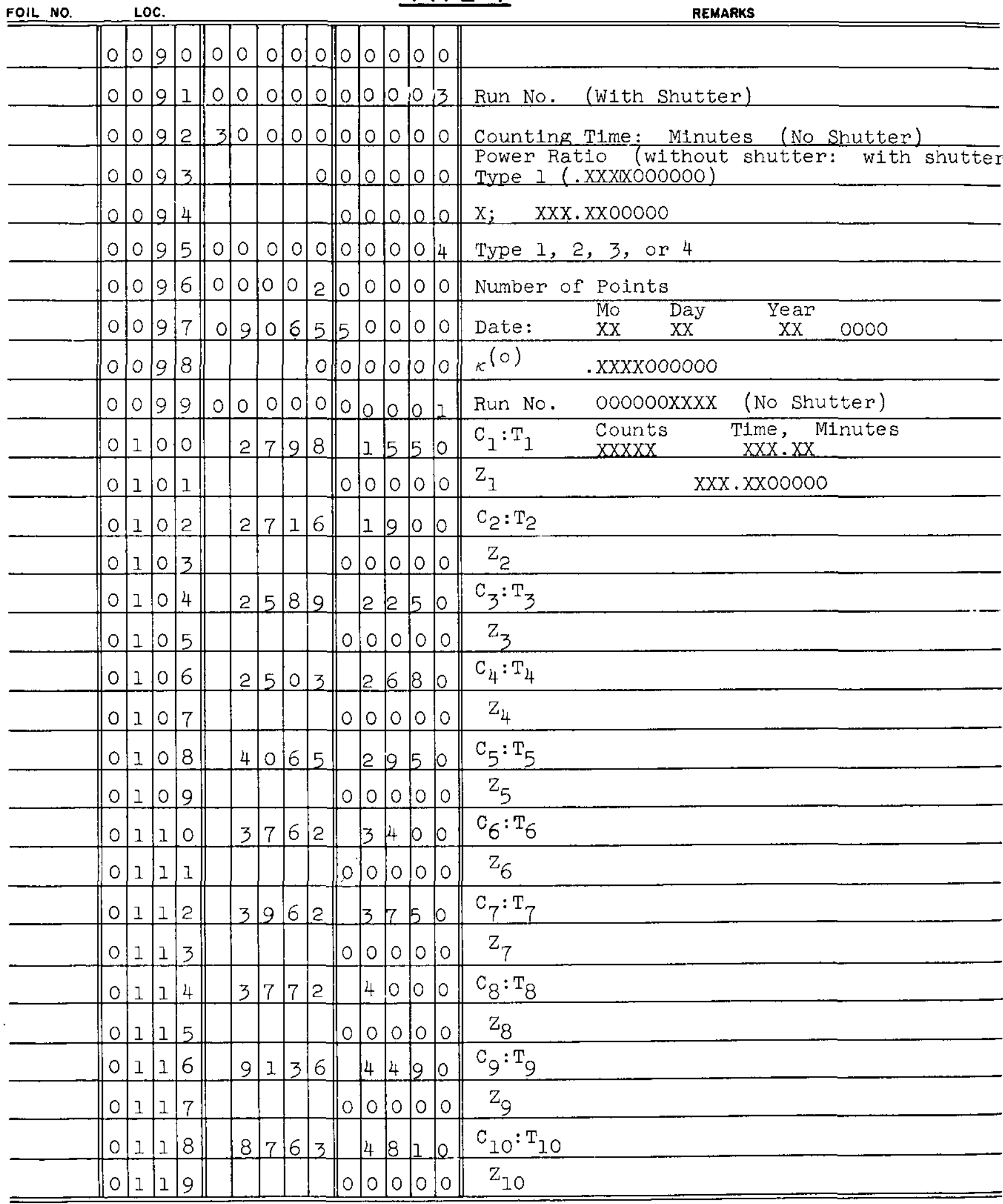


Type 4

Run No. 0001 (Continued)

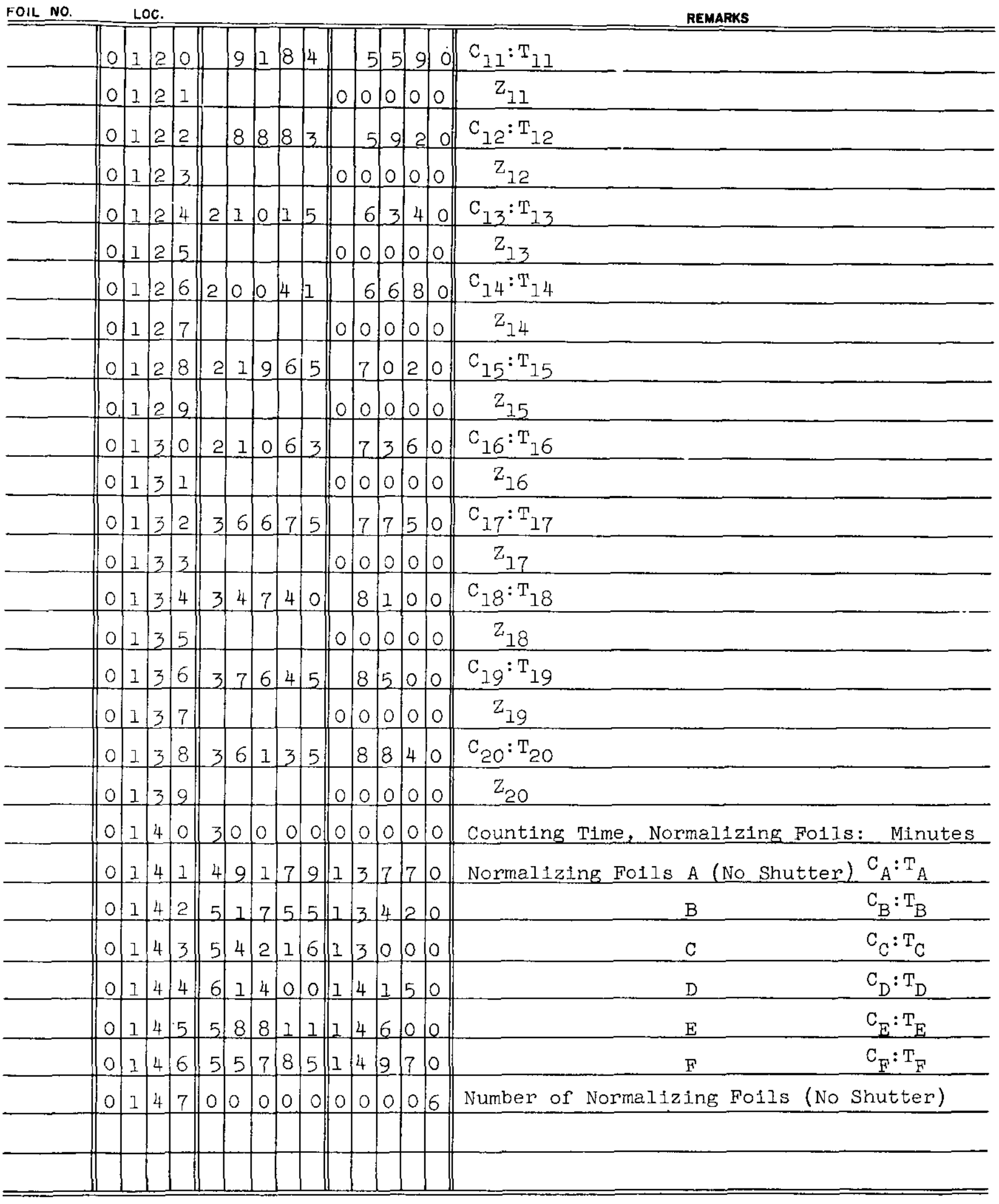




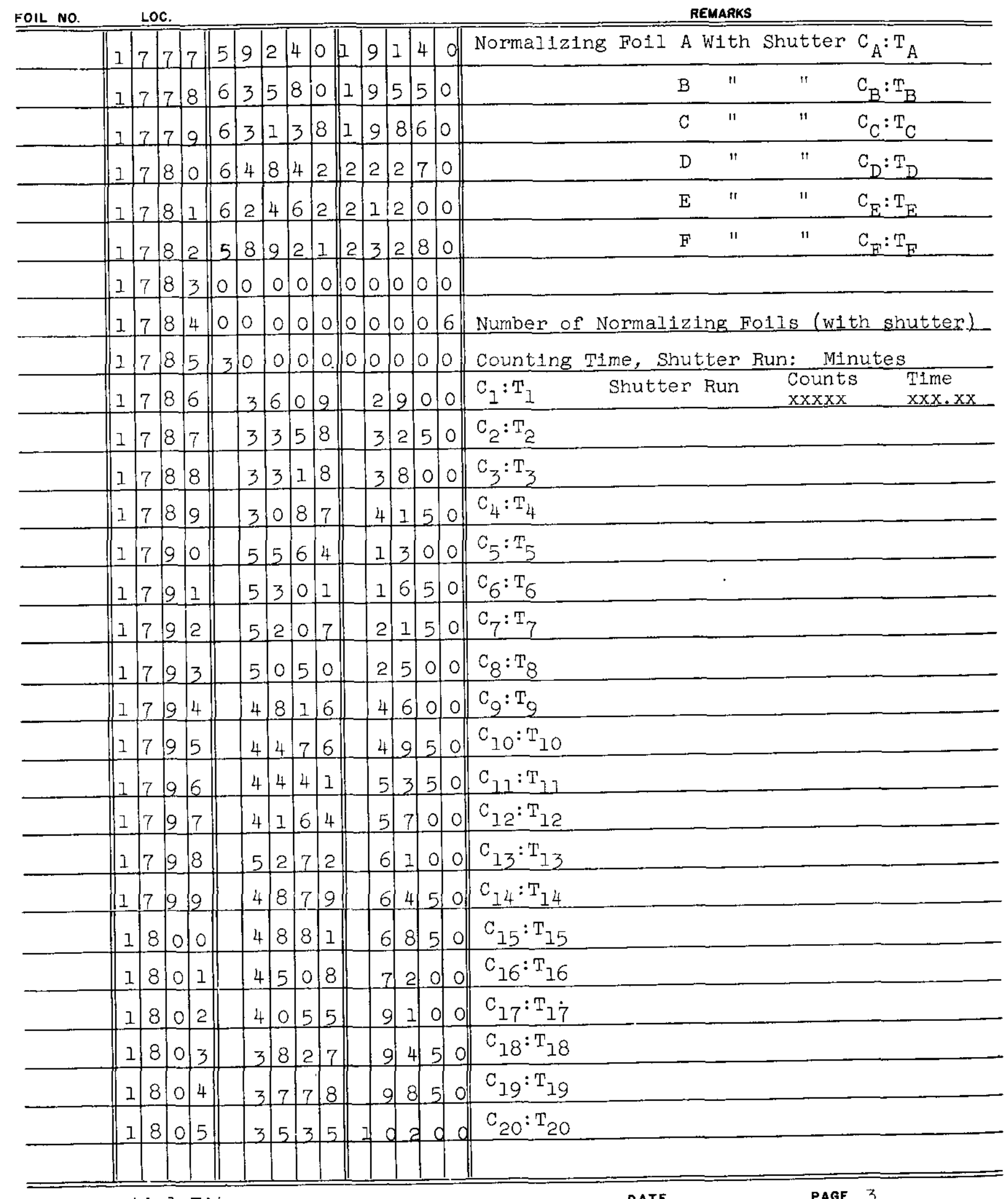


PRINT-OUT FOR TYPE 4

No. of Norm. Foils NS Norm. Foil Data

S Norm. Foll Data

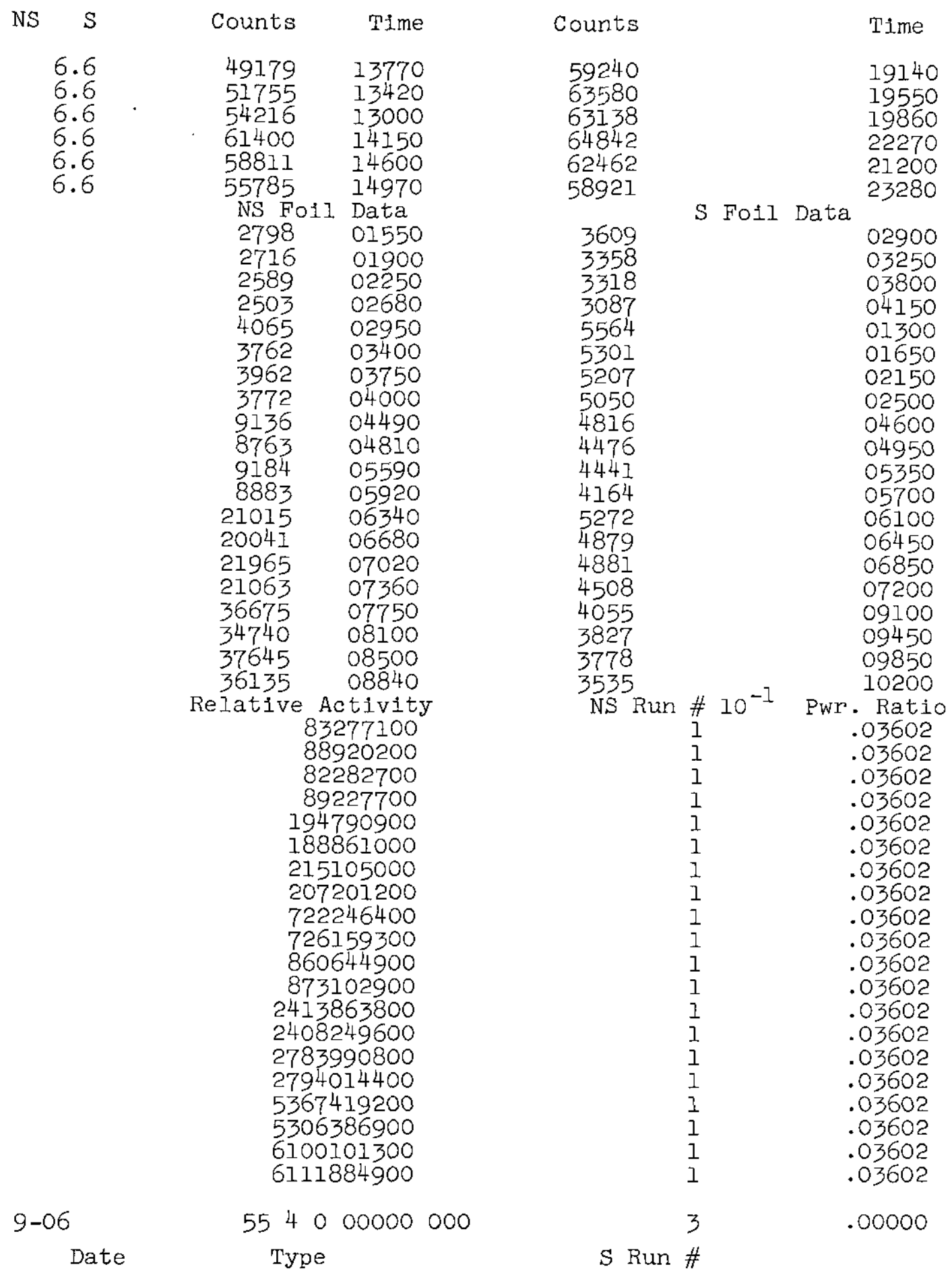


SAMPLE INPUT DATA TYPE 5
Run No. 0091

Without shutter

REMARKS

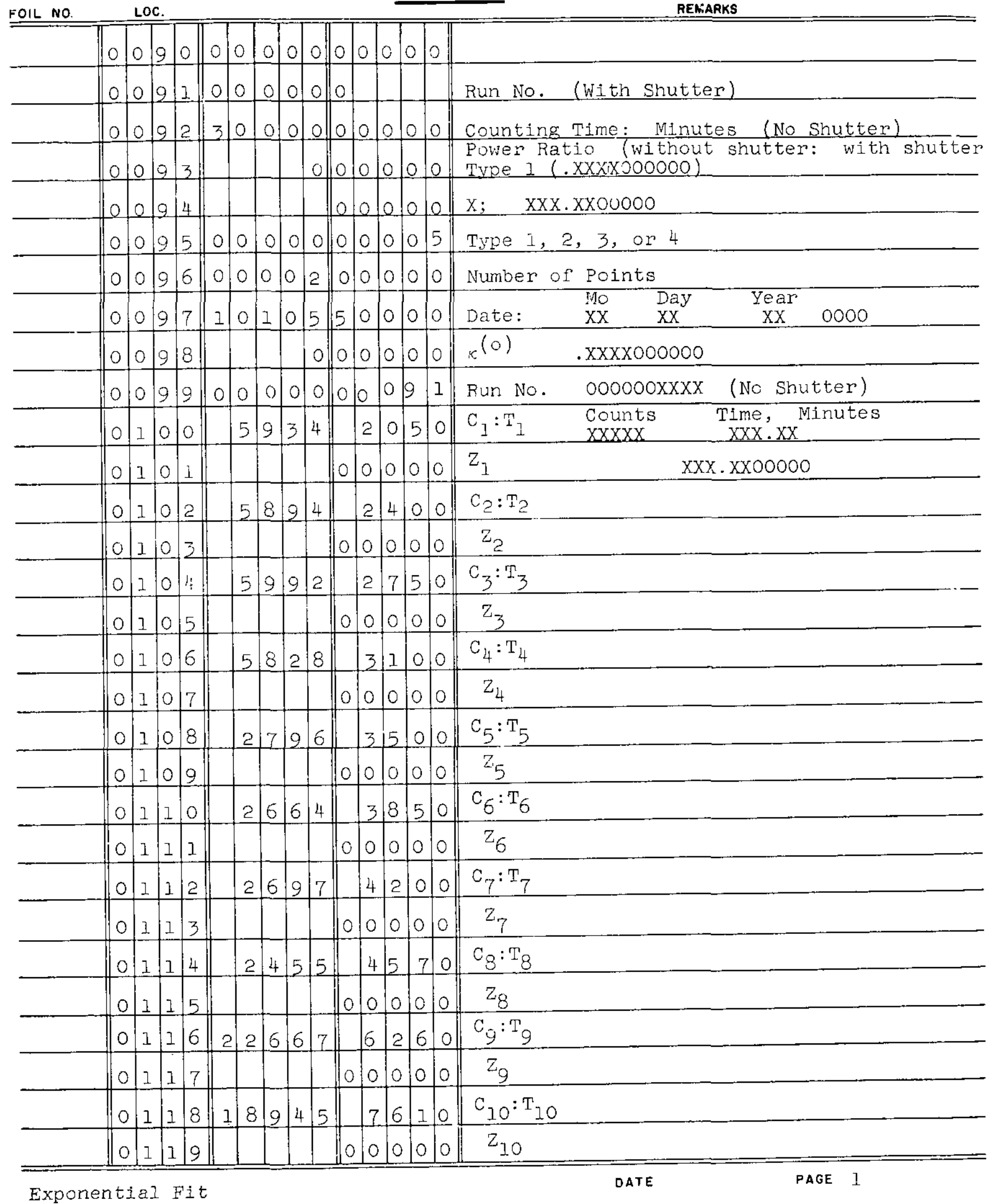




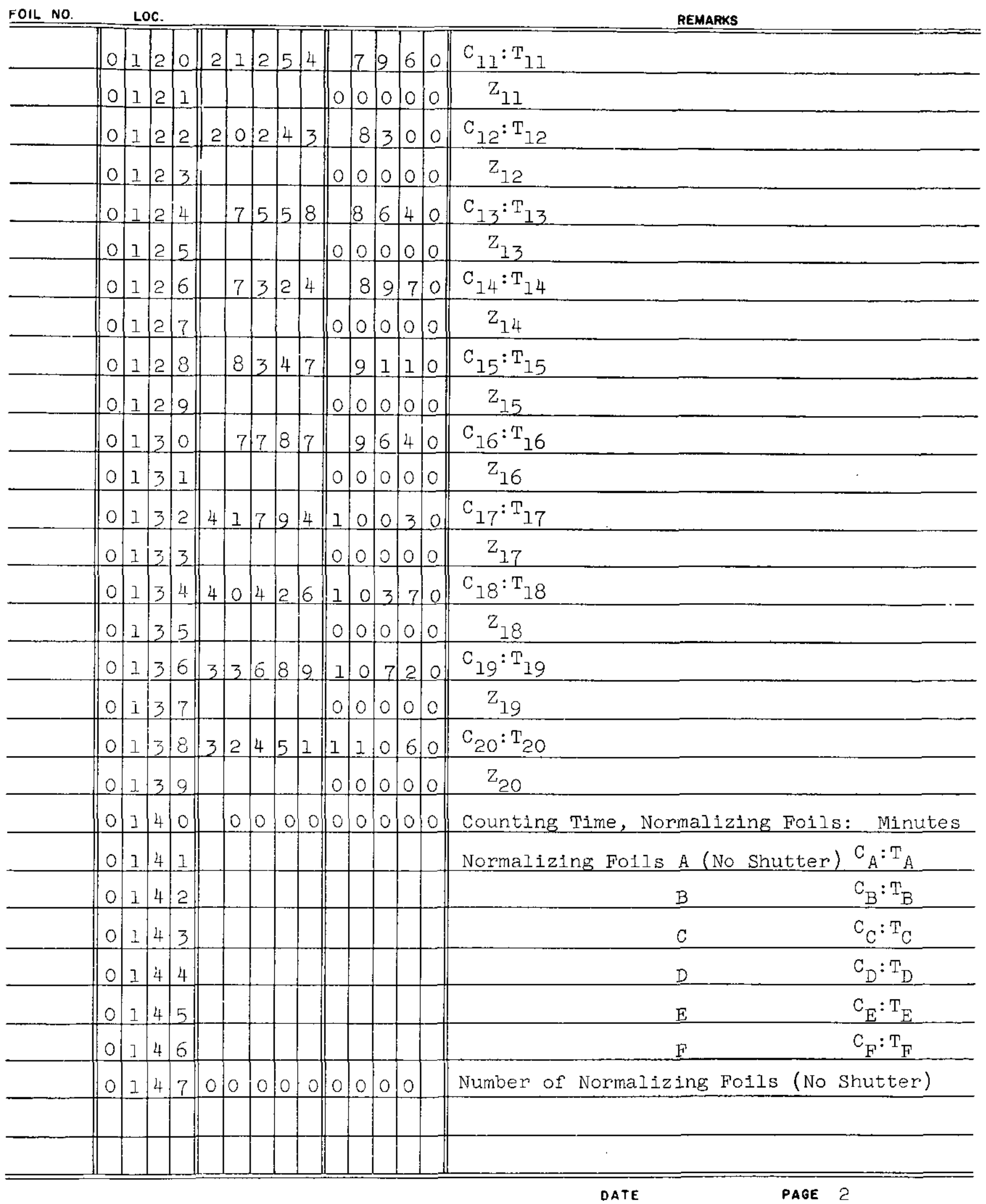


PRINT-OUT FOR TYPE 5

Foil Data

$\begin{array}{rr}\text { Counts } & \text { Time } \\ 5934 & 02050 \\ 5894 & 02400 \\ 5992 & 02750 \\ 5828 & 03100 \\ 2796 & 03500 \\ 2664 & 03850 \\ 2697 & 04200 \\ 2455 & 04570 \\ 22667 & 06260 \\ 18945 & 07610 \\ 21254 & 07960 \\ 20243 & 08300 \\ 7558 & 08640 \\ 7324 & 08970 \\ 8347 & 09110 \\ 7784 & 09640 \\ 41797 & 10030 \\ 40426 & 10370 \\ 33689 & 10720 \\ 32451 & 11060\end{array}$

Relative Activity 422743800 439167400 467038100 475045600 239101900 238246800 252289300 240758500 2825023500 2796027900 3289551000 3269081300 1256886000 1270342400 1475724000 1472136200 8639883000 8715297900 7537578400 7573648300

Run No.

91

91

91

91

91

91

91

91

91

91

91

91

91

91

91

91

91

91

$10-10$

555000000000

Date

Type 


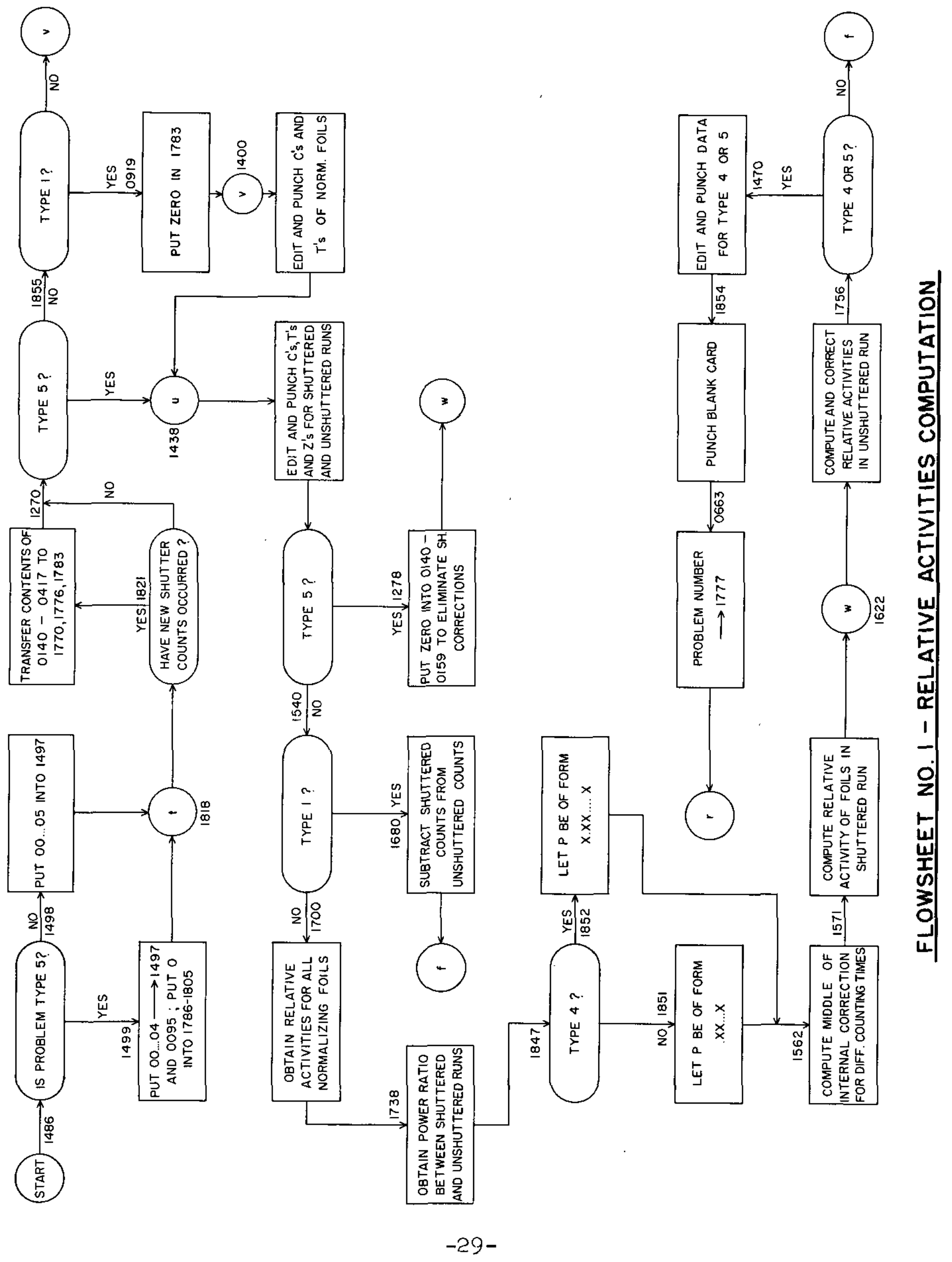




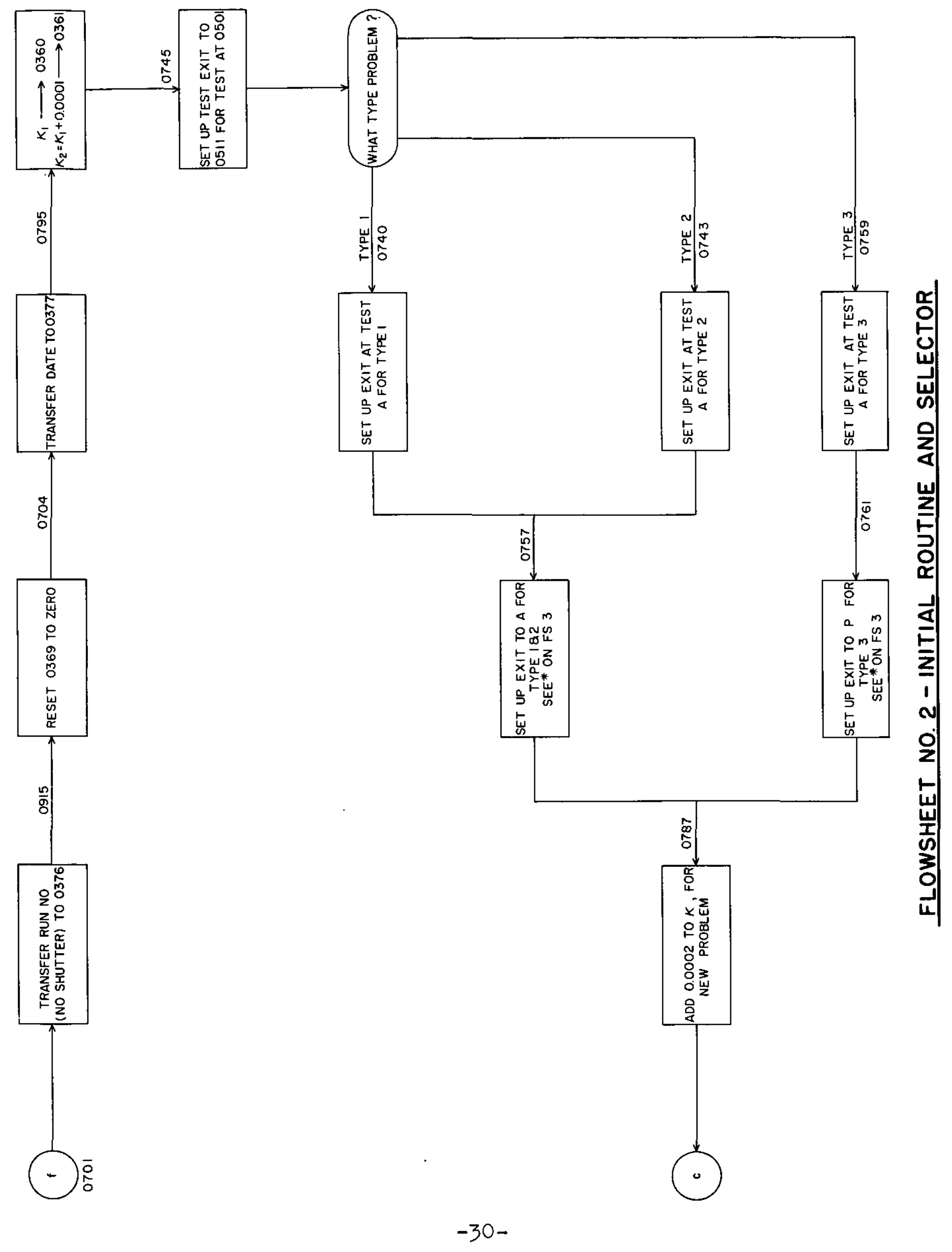




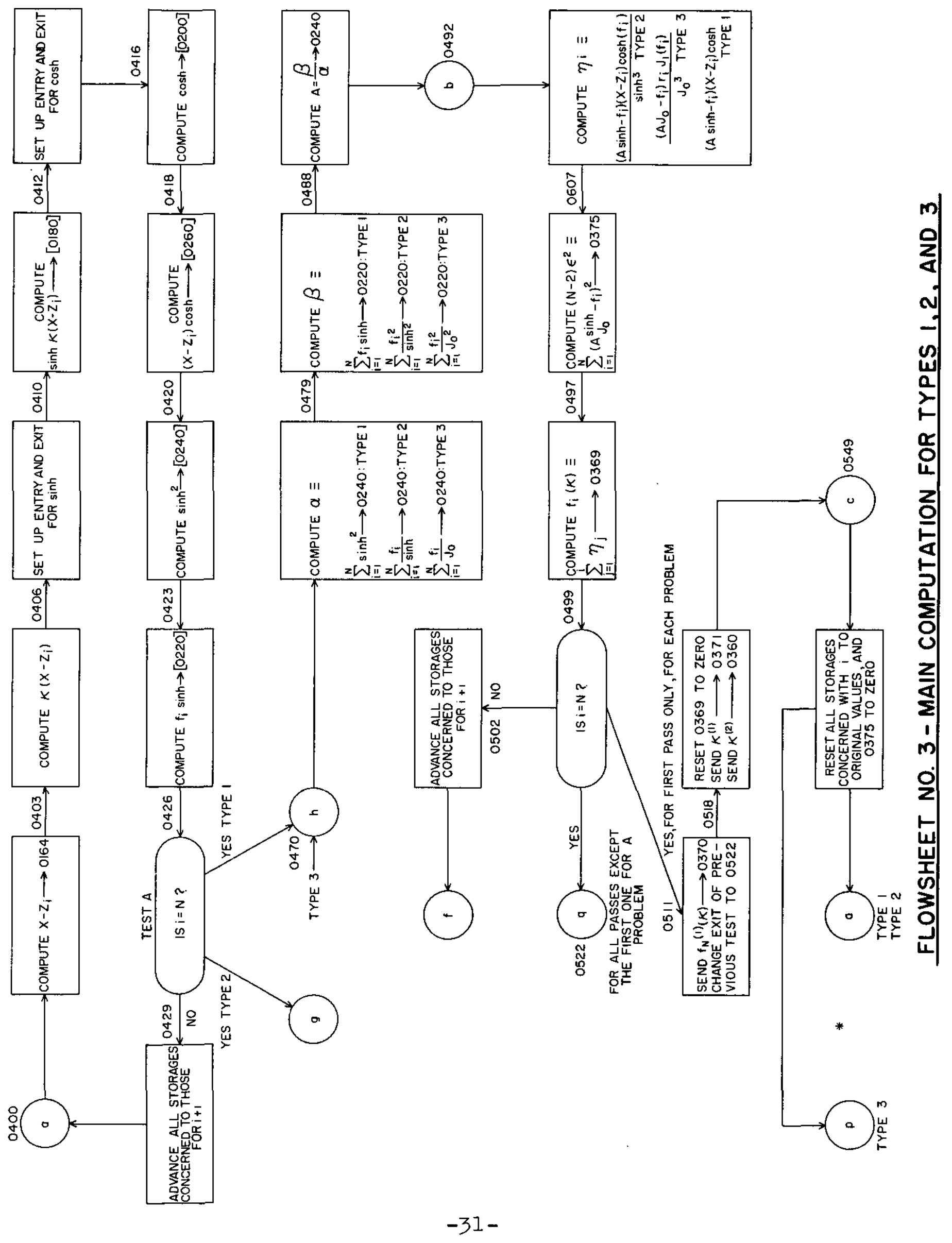




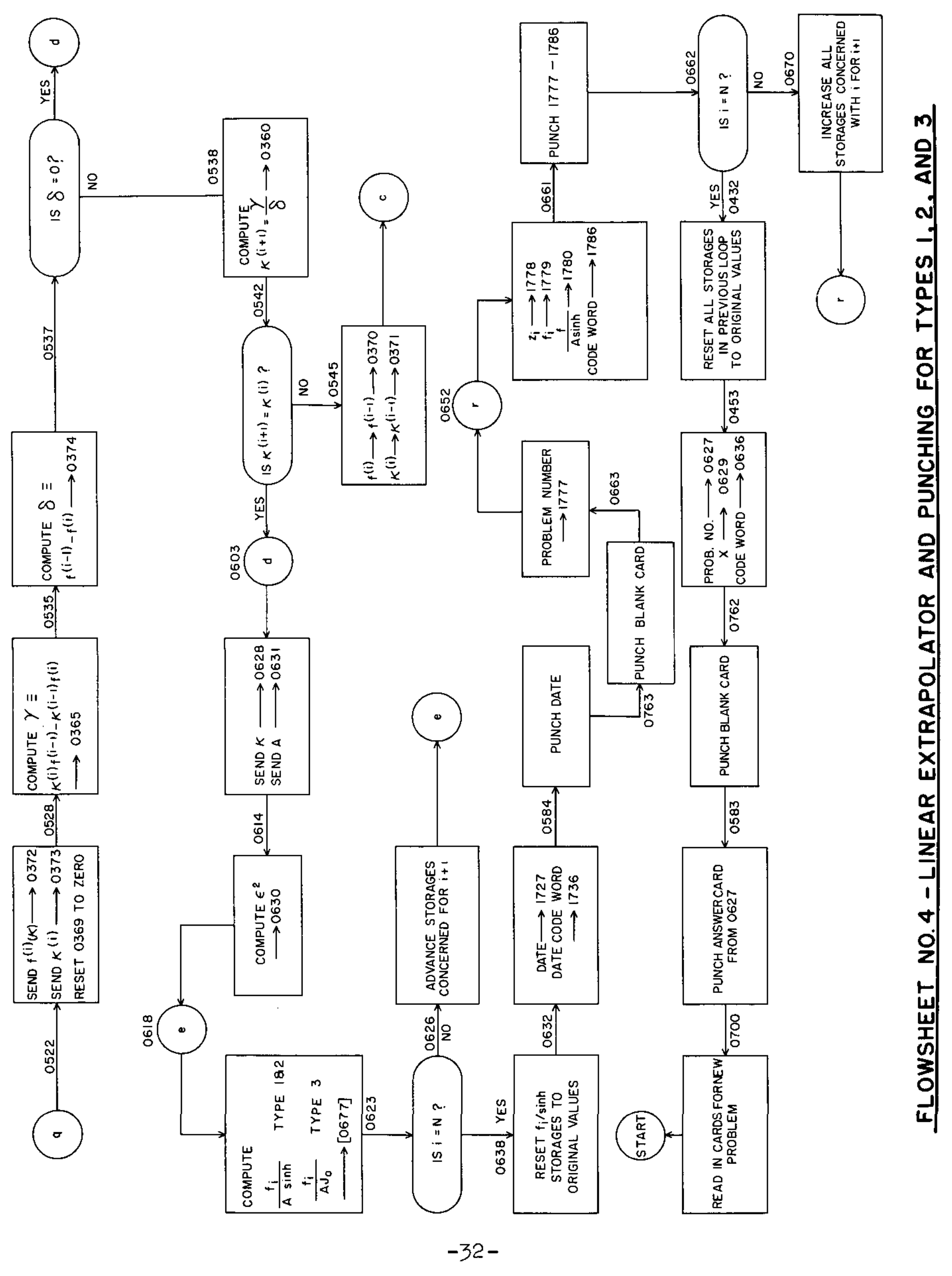




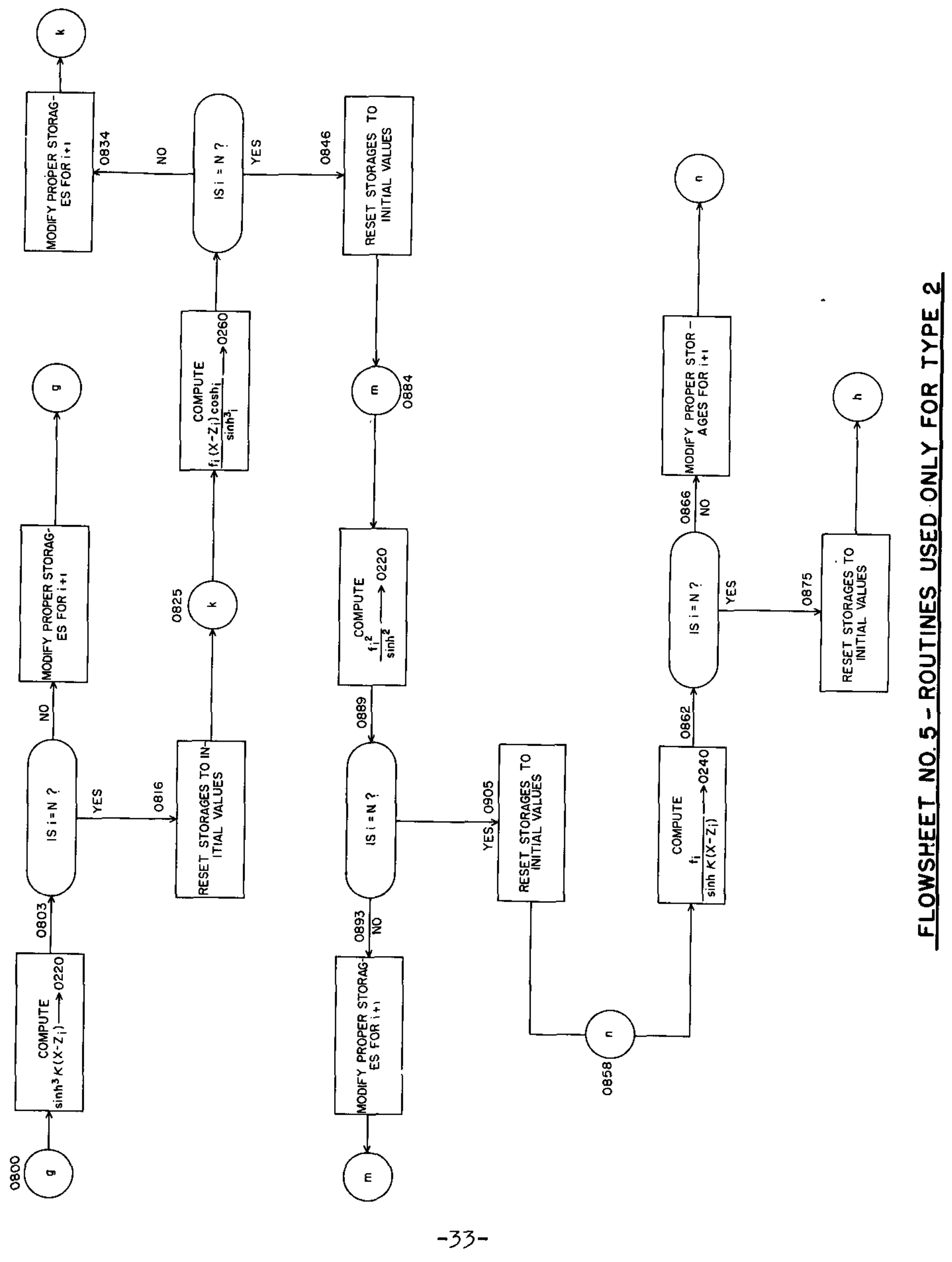




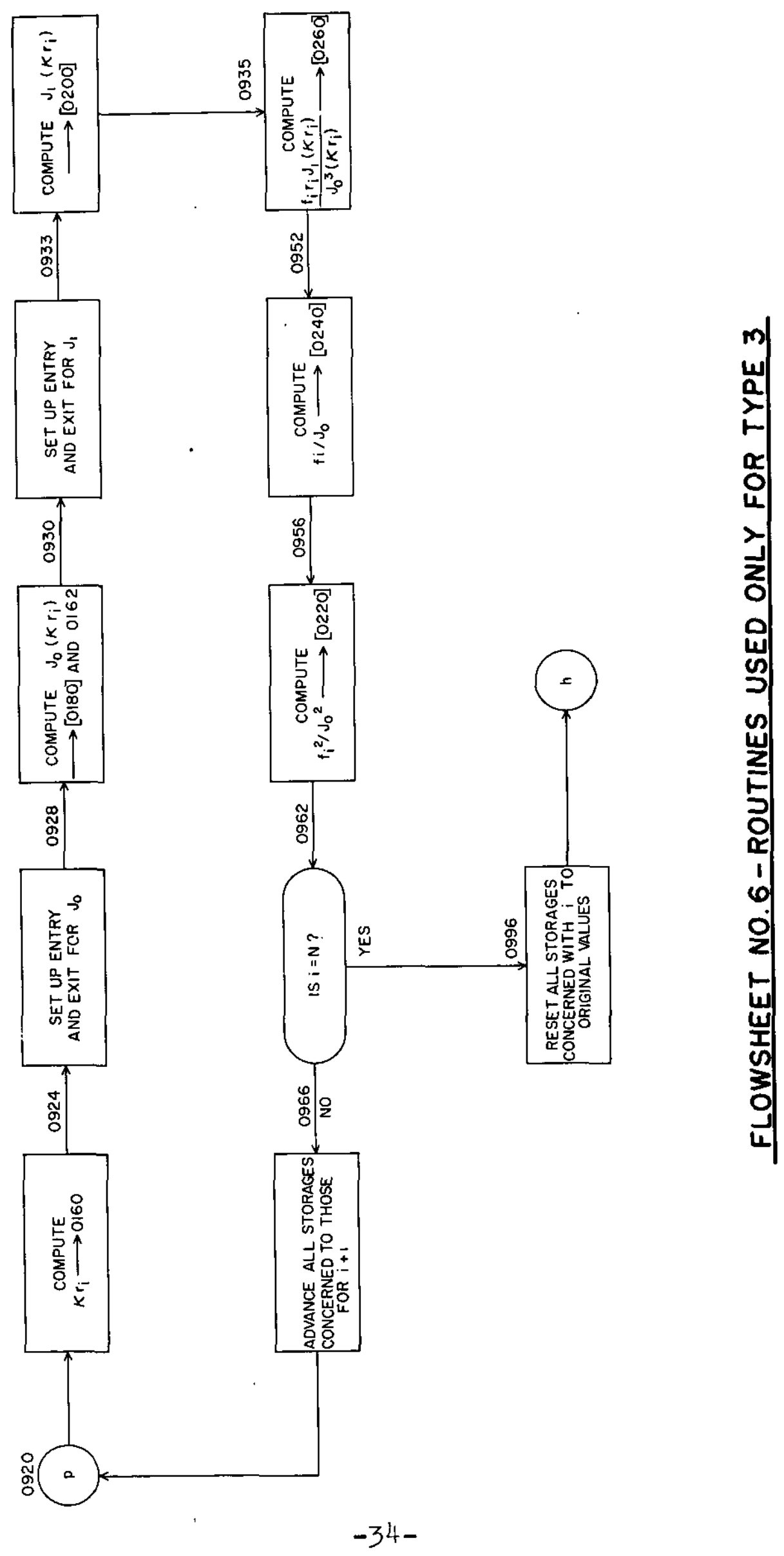

